\title{
Adult Age Differences in Task Switching
}

\author{
Jutta Kray and Ulman Lindenberger \\ Max Planck Institute for Human Development
}

\begin{abstract}
Age differences in 2 components of task-set switching speed were investigated in 118 adults aged 20 to 80 years using task-set homogeneous (e.g., AAAA ...) and task-set heterogeneous (e.g., AABBAABB ...) blocks. General switch costs were defined as latency differences between heterogeneous and homogeneous blocks, whereas specific switch costs were defined as differences between switch and nonswitch trials within heterogeneous blocks. Both types of costs generalized over verbal, figural, and numeric stimulus materials; were more highly correlated to fluid than to crystallized abilities; and were not eliminated after 6 sessions of practice, indicating that they reflect basic and domain-general aspects of cognitive control. Most important, age-associated increments in costs were significantly greater for general than for specific switch costs, suggesting that the ability to efficiently maintain and coordinate 2 alternating task sets in working memory instead of 1 is more negatively affected by advancing age than the ability to execute the task switch itself.
\end{abstract}

Cognitive control processes are generally seen as responsible for the regulation and organization of behavioral activity (Baddeley, 1986; Norman \& Shallice, 1986). Influenced by the neuropsychological research tradition, developmental researchers have become increasingly interested in the role of cognitive control processes for the regulation of behavior and in their relationship to agerelated decrements in fluid intelligence or the mechanics of cognition (e.g., Baltes, 1993). Theoretical considerations about aging models of cognitive control are dominated by the frontal lobe hypothesis of aging, which assumes that age-related decline in intellectual functioning is associated with age-based changes in the frontal lobe (Dempster, 1992; Duncan, 1995; Prull, Gabrieli, \& Bunge, in press). This line of thinking has been primarily influenced by clinical observations of behavioral deficits in frontal lobe patients (Reitan \& Wolfson, 1994; Shallice \& Burgess, 1993; Tranel, Anderson, \& Benton, 1994). Deficits in frontal lobe patients were observed with psychometric tests assumed to require

Jutta Kray and Ulman Lindenberger, Max Planck Institute for Human Development, Berlin, Germany.

This research was part of a dissertation study conducted in the context of project MIND (Memory and Intelligence in Development; principal investigators were Paul B. Baltes, Peter A. Frensch, and Ulman Lindenberger) at the Max Planck Institute for Human Development. In part this research was financially supported by the Berlin-Brandenburg Academy of Sciences.

We are grateful to Paul B. Baltes and Peter A. Frensch for their very valuable comments and helpful discussions. Special thanks go to Annette Rentz-Lühning, Markus Metzler, and Dorothee Schrader for their assistance with data collection, and to Berndt Wischnewski and Manfred Weilandt for programming the experimental tasks and cognitive tests described in this article.

Correspondence concerning this article should be addressed to Jutta Kray, who is now at the Department of Psychology, Humboldt-University of Berlin, Hausvogteiplatz 5-7, D-10117, Berlin, Germany, or to Ulman Lindenberger, Max Planck Institute for Human Development, Lentzeallee 94, D-14195, Berlin, Germany. Electronic mail may be sent to jutta.kray@psychologie.hu-berlin.de or lindenberger@mpib-berlin.mpg.de. control or executive functions, such as the Wisconsin Card Sorting Test, Verbal Fluency Tests, and the Tower of London (Stuss, Eskes, \& Foster, 1994; Tranel et al., 1994). A variety of aging studies primarily used these "frontal lobe tests" as a research strategy, that is, as indicators of age differences in cognitive control functioning. This research strategy is often associated with a lack of clarity and specificity in the definition of executive functions as well as frontal lobe dysfunctions, and with an interchangeable use of the two terms (Tranel et al., 1994). In this context, Baddeley (1996) pointed out that it is not useful to have a simple mapping of executive functions onto an underlying neuroanatomical structure. A better way would be to define the executive component functionally.

With respect to a functional definition of the executive component, developmental researchers were also influenced by models within cognitive psychology, such as the working memory model of Baddeley (1986). Within this model, control processes are attributed to the central executive, which is responsible for controlling and coordinating information from phonological and visuo-spatial subsystems of working memory (Baddeley, 1996). Aging studies have suggested that old adults are particularly impaired in working memory abilities (a) that require the coordination of cognitive processing in complex figural tasks (Frensch, Lindenberger, \& Kray, 1999; Mayr \& KliegI, 1993; Mayr, Kliegl, \& Krampe, 1996) and simple mental arithmetic tasks (Verhaeghen, Kliegl, \& Mayr, 1997), (b) that require the suppression of habitual retrieval strategies and the production of unfamiliar alphabetic sequences in a random generation task (Fisk \& Warr, 1996), and (c) that involve the efficient updating of task elements in a running memory task (Van der Linden, Brédart, \& Beerten, 1994). Thus, in contrast to the frontal lobe approach, these studies were more focused on specific functions or processes of cognitive control involved in the regulation of behavioral activity.

Combining theoretical viewpoints of different research domains, Duncan (1995) highlighted a close relationship among three prominent phenomena-cognitive impairments following lesions in the frontal lobe, the decrements in performance under dual-task situations, and individual differences in fluid intelligence (in the sense 
of Spearman's g; Spearman, 1927). He suggested "that all these problems are indeed closely linked, all concerning the process of goal or abstract action selection under conditions of novelty or weak environmental prompts to behavior" (Duncan, 1995, p. 721).

Cognitive control processes have also been investigated in dualtask situations, interference situations (e.g., the Stroop Task; Stroop, 1935), and task-alternating situations (Allport, Styles, \& Hsieh, 1994; Meiran, 1996; Rogers \& Monsell, 1995). There is ample empirical evidence demonstrating negative adult age differences in (a) dual or divided attention performance (Korteling, 1993; Kramer, Larish, \& Strayer, 1995; Salthouse, Hambrick, Lukas, \& Dell, 1996) and (b) interference measures such as the Stroop Test (Houx, Jolles, \& Vreeling, 1993; Salthouse \& Meinz, 1995; Spieler, Balota, \& Faust, 1996). In addition, there is some evidence to suggest that the ability to alternate between cognitive tasks decreases with age (Brinley, 1965; Chown, 1961; Kramer, Hahn, \& Gopher, 1999; Salthouse, Fristoe, McGuthry, \& Hambrick, 1998; Schaie, Dutta, \& Willis, 1991).

When comparing dual-task, interference, and alternating paradigms, it appears that some variations in demands of cognitive control are achieved by variations in "task uncertainty." Task uncertainty refers to the fact that no definite cue is given for goal or action selection (e.g., Duncan, 1995). Normally, the function of cues is to set up the cognitive system for upcoming actions. Task uncertainty is induced in dual-task situations or in the Stroop Task when stimuli presented trigger more than one relevant task (instruction). In switching paradigms, task uncertainty can also be induced when attributes of both tasks are simultaneously presented by the same stimulus. In this context, empirical studies have shown that costs (in terms of reaction time) of switching between tasks were increased when stimuli of both tasks were identical (Jersild, 1927; Rogers \& Monsell, 1995).

A major problem of the three paradigms used to measure cognitive control abilities concerns limitations in the interpretation of their results because different aspects of cognitive control functioning were confounded. For instance, the ability to share attention in dual-task situations also requires the ability to switch between both single tasks (e.g., Hawkins, Kramer, \& Capaldi, 1992). At the same time, the ability to switch between different tasks was often confounded with different working memory demands in both conditions because switch costs were primarily measured as differences in performance between heterogeneous lists (i.e., ABABABA ...) and homogeneous lists (i.e., AAAAA ... , BBBBB ... ). In heterogeneous lists, it is necessary to maintain task instructions for both $A$ and $B$ in working memory instead of only one task instruction in homogeneous lists (Rogers \& Monsell, 1995). Therefore, Rogers and Monsell (1995) proposed to determine switch costs by comparing the performance of switch trials and nonswitch trials within the same blocks.

\section{Present Study}

The implications for the investigation of age-based limitations in cognitive control in the present study are theoretical and methodological ones. First, cognitive control processes seem to be particularly required in situations of task uncertainty in which no cue is given for the selection of the relevant action (Duncan, 1995), that is, in situations that produce problems in selecting which action or task to perform at any given moment. Therefore, we constructed the stimulus materials used in the present study such that stimuli for Tasks A and B were identical (see Figure 1). Thus, demands on internally triggered action selection were high because no external cue was given for the selection of the currently relevant response. In addition, no cue for keeping track of the task sequence was given. Therefore, participants knew only from prior instruction which task to perform at any given moment. We implemented this task characteristic to observe age differences in cognitive control processing that are maximally independent of external cueing from the environment. We assumed that rapid switches between task sets without external cues impose high demands on internal action control.

Second, we examined age differences in cognitive control by complementing the switching paradigm (Rogers \& Monsell, 1995) with the measurement of a nonswitch baseline. The goal was to assess cognitive control components that were specifically related to the switch situation and control components related to the dual-task situation in general. Specifically, we administered taskhomogeneous and task-heterogeneous blocks in the same experiment to compare switch costs as measured in the narrow sense with more general aspects of cognitive control in dual-task performance. In task-homogeneous blocks, participants performed either Task A (e.g., classifying shapes as rectangles or triangles) or Task B (e.g., classifying figures as colored or gray). In taskheterogeneous blocks, participants alternated between the two tasks, A (classifying shapes) and B (classifying colors), in predictable sequences of AABBAABB .... The stimuli (e.g., colored figures, such as a red rectangle or a gray triangle) were presented in successive trials on the computer screen (see Figure 1). The combination of task-homogeneous and task-heterogeneous blocks allowed a comparison of two different aspects involved in task switching. One aspect concerns control processes that are required for the initiation and execution of the actual task-set shift. Costs of this switching process (Monsell, 1996) were estimated as differences between mean reaction times in switch trials and mean

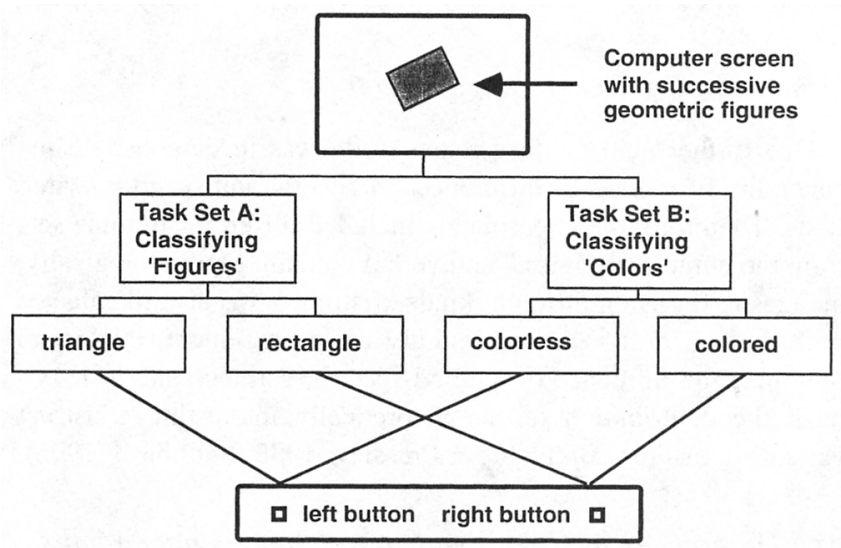

Figure 1. The Switching Paradigm: Participants performed two simple tasks, A (e.g., classifying figures) and B (e.g., classifying colors), in a predictable sequence of AABBAABB and so on. The stimuli were presented on successive trials in the screen. Task Set A requires classifying a figure as rectangle or triangle, and Task Set $B$ requires classifying a figure as colored or gray. The attributes "triangle" and "gray" were mapped onto the left response button, and the attributes "rectangle" and "colored" were mapped onto the right response button. 
reaction times in nonswitch trials within task-heterogeneous blocks and were termed specific switch costs. Another aspect refers to control processes that are required for the regulation of cognitive processing associated with the general switch situation. Costs of the general task-switching situation were determined by computing differences between mean reaction times in task-heterogeneous trials and mean reaction times in task-homogeneous trials and were termed general switch costs. These costs were assumed to reflect the ability to maintain two task-set instructions (e.g., action routines, such as stimulus-response mappings for Tasks A and B) and to coordinate these task instructions with information about the actual position in the task sequence in the task-heterogeneous blocks. Given their greater demands on working memory, we expected age differences in general switch costs at least as large as age differences in specific switch costs.

Third, on the basis of the theoretical considerations of Duncan (1995), we expected that interindividual differences in both general and specific switch costs would show significant relations to general intelligence as assessed by a variety of cognitive tests. A second rationale for linking cognitive control to the intellectualability factor space was to explore ability-specific and age-based relations between the two sets of measures. Specifically, the twocomponent model of life span cognition (Baltes, 1993) predicted stronger relationships to intellectual abilities in the broad fluid domain (cognitive mechanics) than to intellectual abilities in the broad crystallized domain (cognitive pragmatics). Findings of a recent study by Salthouse et al. (1998) support these theoretical considerations with respect to what is termed specific task switching in the context of the present study. They examined relations among specific task switching, perceptual speed, and several cognitive variables and found (a) that specific task switching formed a distinctive factor in the intellectual-ability factor space and (b) that specific task switching was substantially correlated with perceptual speed and reasoning (from the fluid domain) but was less highly correlated with vocabulary measures (from the crystallized domain). We also aimed to investigate whether task-switching ability can be differentiated into specific and general components.

\section{Demonstrating General Age Effects}

One further goal of the present study was to demonstrate the generality of individual differences in general and specific switch costs. Therefore, the experiments included different stimulus sets from the numerical, figural, and verbal domain. Methodologically, the reason for using different kinds of stimuli was also to enhance both the reliability and the validity of measurement, that is, to minimize the influence of method-specific variance and to maximize the contribution of the theoretically interesting construct variance (Rushton, Brainerd, \& Pressley, 1983; Salthouse, 1996).

\section{Age Differences in Cognitive Control Near Upper Limits of Cognitive Functioning}

We used an extensive practice design comparable to the testingthe-limits approach (Baltes \& Kliegl, 1992; Kliegl \& Baltes, 1987) in order to assess age differences that are closer to biological aging losses by comparing young and old adults near upper limits of performance. Specifically, the testing-the-limits approach aims at separating age differences in cognitive abilities that are due to aging losses in experience and practice from biological aging losses (Baltes, Staudinger, \& Lindenberger, 1999; Lindenberger \& Baltes, 1995; Salthouse, 1991). The reduction of general and specific switch costs with increasing practice would suggest plasticity of cognitive control abilities in young and old adults and would allow us to compare the amount of positive modifiability of cognitive control performance between young and old adults at the end of practice. At the same time, we assumed that general task-switching performance as well as specific task-switching performance would be associated with the "mechanic" components, or architectural constraints, of our cognitive system. Therefore, we expected that general and specific switch costs would be robust against large amounts of practice.

\section{Age Differences in Task Preparation}

Of further interest in the present study was the effect of task preparation when increasing response stimulus interval (RSI). The manipulation of RSI was based on considerations that with long RSIs, participants can engage in cognitive control processing prior to the appearance of the next stimulus (Rogers \& Monsell, 1995). In other words, participants have more time to organize their own processing in advance. Empirical studies have shown that costs of switching were reduced when participants had sufficient time to prepare the next task switch (Meiran, 1996; Rogers \& Monsell, 1995; but see Allport et al., 1994). Rogers and Monsell (1995) argued that the time costs of a task-switch index, in part, the duration of an endogenously driven reconfiguration process. In contrast to the stimulus-triggered (exogenous) component, the endogenous component of task control can become active before the next stimulus appears on the screen because the task sequences in their experiments were predictable. Therefore, longer RSIs should lead to reduced switch costs and to a change of the relative importance of endogenous and exogeneous processes. Recent taskswitching studies showed that both young and old adults benefit from fewer time constraints during task switching; that is, a significant reduction of switch costs with increasing RSI was observed in both age groups (Kramer et al., 1999; Meiran, Gotler, \& Perlman, 1998). However, findings regarding RSI and interactions with age are inconsistent because Kramer et al. (1999) also found that old adults were not able to use increased preparation time when no cue was provided in order to keep track of the task sequence.

In summary, the main goals of the present study were (a) to explore age differences in two cognitive control abilities (indexed by general and specific switch costs) as a function of stimulus type, extensive practice, and the amount of time between task switching and (b) to determine how age differences in cognitive control functioning are related to age differences in intellectual functioning.

\section{Method}

\section{Participants}

One hundred twenty adults (age range $=20-80$ years; mean age $=49.7$ years) participated in all eight sessions. The sample was stratified by age with 20 participants in six age groups $(20-30,31-40,41-50,51-60$, $61-70,71-80$ ) and by the same proportion of women to men in each age group. Except for the oldest age group, with 17 women and 3 men, there 
Table 1

Means, Standard Deviations, and Age-Group Comparisons ( $t$ Tests) for Health, Education, Vocabulary, and Digit-Symbol Substitution Test

\begin{tabular}{|c|c|c|c|c|c|c|c|c|c|c|}
\hline \multirow[b]{4}{*}{ Variable } & \multirow{2}{*}{\multicolumn{6}{|c|}{ Age group }} & \multicolumn{4}{|c|}{ Age-group comparison } \\
\hline & & & & & & & \multirow{2}{*}{\multicolumn{2}{|c|}{$\begin{array}{l}\text { Young vs. } \\
\text { middle + old }\end{array}$}} & \multirow{2}{*}{\multicolumn{2}{|c|}{$\begin{array}{l}\text { Middle-aged vs. } \\
\text { old }\end{array}$}} \\
\hline & \multicolumn{2}{|c|}{ Young } & \multicolumn{2}{|c|}{ Middle-aged } & \multicolumn{2}{|c|}{ Old } & & & & \\
\hline & $M$ & $S D$ & $M$ & $S D$ & $M$ & $S D$ & $t^{\mathrm{a}}$ & $p$ & $t^{a}$ & $p$ \\
\hline$n$ & 39 & & 40 & . & 39 & & & & & \\
\hline$\%$ female & 62.5 & & 60.0 & & 74.4 & & & & & \\
\hline Age & 29.6 & 5.8 & 50.3 & 6.2 & 69.5 & 5.4 & & & & \\
\hline \multicolumn{11}{|c|}{ Self-reported health ${ }^{b}$} \\
\hline Physical & 2.1 & 0.9 & 2.4 & 0.8 & 2.5 & 0.8 & +2.1 & $n s$ & +0.9 & $n s$ \\
\hline Mental & 2.0 & 0.6 & 2.2 & 0.7 & 2.3 & 0.6 & +2.5 & ns & +0.6 & ns \\
\hline Education $^{c}$ & 12.0 & 1.4 & 11.7 & 1.5 & 11.7 & 1.5 & -1.0 & $n s$ & -0.1 & ns \\
\hline Vocabulary & 25.6 & 2.8 & 24.8 & 3.4 & 24.6 & 2.8 & -1.5 & $n s$ & -0.2 & $n s$ \\
\hline Digit Symbol & 61.3 & 8.5 & 52.5 & 10.1 & 45.1 & 8.3 & -7.1 & $<.01$ & -3.7 & $<.01$ \\
\hline
\end{tabular}

a $d f=115$.

be assessed self-reported health with a Likert scale ranging from 1 (excellent) to 5 (very poor).

${ }^{\mathrm{c}}$ Education refers to years of schooling. The six age decades were collapsed into three age groups: (a) Young adults (age range: $20-40$ years), (b) middle-aged adults (age range: $41-60$ years), and (c) old adults (age range: 61-80 years).

were 12 women and 8 men in each age group. The uneven gender distribution in the oldest age group was due to difficulties in recruiting older men. ${ }^{1}$ We recruited the sample through newspaper advertisements. All participants received 180 DM (about U.S. $\$ 100$ ) for participating in the entire experiment, which corresponded to about 20 DM (about U.S. \$12) per hour. We excluded two research participants, one 36-year-old man and one 74-year-old woman, from further analysis because they performed more than three standard deviations below the average level of their age group under most experimental conditions. Exclusion of these participants' data did not change the overall pattern of results. Demographic characteristics of the final sample of 118 participants are summarized in Table 1. For descriptive purposes, the six age groups were collapsed into three: (a) young adults ( $20-40$ years; $n=39$ ); (b) middle-aged adults ( $41-60$ years; $n=40$ ); and (c) old adults ( $61-80$ years; $n=39$ ). Orthogonal contrasts for age group (young adults vs. middle-aged and old adults, and middle-aged adults vs. old adults) were used to compare the three groups (see Table 1). Participants in all three age groups reported themselves to be in good physical and mental health, with no significant differences between pairs of age groups. Furthermore, no significant age differences were observed in years of formal education or vocabulary subtest performance. In line with previous aging studies, negative age differences were obtained for the Digit Symbol Substitution. ${ }^{2}$ Young adults obtained significantly higher scores than middle-aged and old adults, $t(115)=-7.1, p<.01$, and middle-aged adults obtained significantly higher scores than old adults, $t(115)=-3.7$, $p<.01$.

\section{Measures}

We administered a total of 17 cognitive tests to measure six specific intellectual abilities: Reasoning (Raven's Advanced Progressive Matrices Test, Figural Analogies, Letter Series), perceptual speed (Digit Letter Test, Digit Symbol Substitution, Identical Pictures), knowledge (Spot-a-Word, Vocabulary, Practical Knowledge), primary memory (Digit Span, Word Span, Visual Span), working memory (Alpha Sorting, Digit Sorting, Animal Sorting), and inhibition (Color-Stroop, Position-Stroop). Four tests (Spot-a-Word, Letter Series, Identical Pictures and Figural Analogies) were administered using a Macintosh SE/30 computer equipped with touch-sensitive screen. The following tests were developed in the context of the Berlin Aging Study: Figural Analogies, Letter Series, Digit Letter Test, Digit Symbol Substitution, Identical Pictures, Spot-a-Word, ${ }^{3}$ Vocab- ulary, Practical Knowledge. Those tests followed exactly the administration as described by Lindenberger, Mayr, and Kliegl (1993). In addition, we also used the original version of Raven's Advanced Progressive Matrices Test (Raven, Court, \& Raven, 1987). All other tests that were adapted from other sources or that we developed are described below.

Digit Span (Wechsler, 1982). The test consisted of 18 items. Stimuli were numbers between 1 and 12 . Numbers (memory span) ranging from three to eight were presented auditorily at a rate of $1 \mathrm{~s}$ per number. Participants were asked to repeat the numbers in order of their presentation. Three trials for each memory span were administered. The score used corresponded to the longest series of numbers for which at least two trials were correctly repeated.

Word Span. Similar to the Digit Span test, words ranging from three to eight were presented auditorily at the rate of $1 \mathrm{~s}$ per word. As stimuli, 12 different words (house, child, grass, picture, fish, dress, silver, boot, wolf, song, whale, stone) were used. Participants had to repeat the words in order of their presentation. The same scoring system was used as for the Digit Span version.

Visual Span. In analogy to the other two primary memory tests, pictures (ranging. from three to eight) were presented successively on a computer screen with an interstimulus interval of $350 \mathrm{~ms}$. We used 12 different pictures (pen, tree, letter, scissors, fish, moon, apple, swan, blackboard, bus, book, sun). Participants had to remember all pictures in their order of presentation, and the same scoring system as before was used.

Alpha Sorting (Craik, 1986). All three working memory measures consisted of 18 items. As in the Word Span test, words ranging from three to eight were presented successively. Participants had to remember the first letter of each word and repeat them by sorting the letters in alphabetic order. As stimuli, 20 different words were used (Auto, Bach, Cola, Dach, Ente, Film, Glas, Hemd, Igel, Kamm, Laub, Mund, Nase, Obst, Rose, Sofa,

\footnotetext{
${ }^{1}$ ANOVAs with gender as a covariate revealed that gender did not interact with the variables of interest.

${ }^{2}$ Description or references regarding tests and tasks are provided below.

${ }^{3}$ In the present study, the subtest Spot-a-Word included 35 instead of only 20 items (see Lindenberger, Mayr, \& Kliegl, 1993) in order to avoid ceiling effects.
} 
Table 2

Stimulus Materials and Task Sets

\begin{tabular}{|c|c|c|c|c|c|}
\hline \multirow{2}{*}{$\begin{array}{l}\text { Stimulus } \\
\text { material }\end{array}$} & \multirow{2}{*}{$\begin{array}{c}\text { Example } \\
\text { items }\end{array}$} & \multicolumn{2}{|c|}{ Task Set } & \multicolumn{2}{|c|}{ Response } \\
\hline & & $\mathrm{A}$ & B & Left & Right \\
\hline Digit strings & 2352 & Numerical size & Equal digits & $\begin{array}{l}\text { First two smaller } \\
\text { All digits unequal }\end{array}$ & $\begin{array}{l}\text { First two larger } \\
\text { Two digits equal }\end{array}$ \\
\hline Colored figures & Red rectangle & Form & Color & $\begin{array}{l}\text { Triangle } \\
\text { Shades of gray }\end{array}$ & $\begin{array}{l}\text { Rectangle } \\
\text { Colored }\end{array}$ \\
\hline Words & Dog & Category & Syllables & $\begin{array}{l}\text { Inanimate } \\
\text { One }\end{array}$ & $\begin{array}{l}\text { Animate } \\
\text { Two }\end{array}$ \\
\hline
\end{tabular}

Note. Correct responses to example items are italicized.

Tuch, Vase, Wald, Zaun). The score corresponded to the longest series of at least two correctly repeated word lists (working memory span).

Digit Sorting. We auditorily presented a list of numbers ranging from three to eight. Participants had to repeat the numbers by sorting them according to numerosity. Numbers between 1 and 20 were used as stimuli. Again, we used the same scoring system as for the Alpha Sorting version.

Animal Sorting. In this test, we auditorily presented a list of animals (ranging from three to eight). Participants were asked to repeat the animals by sorting them in order of their body size. The mental representation of body-size differences of nine animals (flea, ant, snail, mouse, hamster, cat, horse, elephant, giraffe) was determined prior to testing. Participants were asked to sort nine pictures of these animals according to their real body size from smallest to largest. If the participants' representation differed from the one mentioned above, we used their mental representation for scoring. We used the same scoring system as with Digit Sorting.

Color-Stroop (adapted from Salthouse \& Meinz, 1995). The stimulus materials consisted of three cards containing six columns of six stimuli each (i.e., 36 items). The stimuli were colored words (e.g., red, blue, green, yellow) or characters (e.g., XXXX) of $5 \mathrm{~mm}$ height surrounded by rectangles of $17 \times 32 \mathrm{~mm}$. Participants were instructed to name the ink colors of the stimuli as quickly as possible. On Card A, color names and ink colors of the items were compatible; on Card B, colored characters (e.g., $\mathrm{XXXX}$ ) were used as neutral stimuli; and on card $\mathrm{C}$, color names and ink colors of the stimuli were incompatible. The answers of each card were timed with a stopwatch, and errors were documented. The three cards, A, $B$, and $\mathrm{C}$, were shown in fixed order. We computed the color-interference score as difference in mean reaction time of Card $\mathrm{C}$ minus mean reaction time of Card B.

Position-Stroop. This test was identical in format to the Color-Stroop version. Words (e.g., left, right, above, below) or characters (e.g., XXXX) of $3 \mathrm{~mm}$ height were used as stimuli. As in the Color-Stroop version, the position names and the position of a word on the card could be identical or different. The task instruction was always to report the position of the stimuli. On Card A, position name and position of the items were incompatible; on Card B, the positions were compatible; and on Card C, the X characters were used as neutral stimuli. The answers of each card were again timed with a stopwatch, and the errors were counted. We computed the position-interference score as difference in mean reaction time of Card A minus mean reaction time of Card $C$.

Simple reaction time. Similar to a procedure used by Hertzog, Cooper, and Fisk (1996), participants were presented a gray square in the center of the computer screen. We asked them to respond as quickly as possible to the appearance of this gray square by pressing a button. Research participants responded with their left index finger in the first and third blocks, and with their right index finger in the second and fourth blocks. Each stimulus was preceded by a random foreperiod of either $600,950,1,300$, or $1,650 \mathrm{~ms}$ in order to avoid the anticipation of the stimulus. Participants first worked through a practice block of 10 trials for each index finger. Then, four blocks of 20 trials were given. The scores were mean reaction time measured with the left index finger, mean RT measured with the right one, or mean reaction time aggregated across both conditions.

Tapping. We asked participants to press a button as often as possible within a time window of $15 \mathrm{~s}$. In the first block, participants pressed the button as often as possible with the left index finger. In the second block, they pressed the button as often as possible with the right index finger. In the third and last block, we instructed them to press buttons as often as possible alternately with the left and the right index finger. This succession of three blocks was repeated three times. The scores used were the number of pressed buttons within $15 \mathrm{~s}$ separately for the three conditions (left, right, alternation) or aggregated across all three conditions.

\section{Measurement of Cognitive Control}

Apparatus. We used Apple Macintosh 7100/66AV Power PCs for stimulus presentation and response collection. The stimuli were presented on Sony Multiscan 15 sf color monitors (256-color mode) with light-gray background. Responses were given with two black response buttons connected to a National Instrument NB-MIO-16 multifunction LO board with ms timer.

Materials. We developed three parallel sets of stimuli (see Table 2). Stimuli (digit strings, geometrical figures, or words) were presented in successive trials on the computer screen. In the numerical task, participants alternated between two numerical decisions based on four-digit strings (e.g., 2352). In Task A, they had to decide whether the first two-digit number (e.g., 23) was larger or smaller than the second two-digit number (e.g., 52). In Task B, they had to decide whether all four digits were different from each other, or whether two digits were identical. In the figural task (see Figure 1), we asked participants to decide whether the figure was a triangle or a rectangle (Task A), or whether the figure was colored or gray (Task B). Finally, in the verbal task, participants decided whether a word (e.g., dog) referred to something animate or inanimate (Task A), or whether the number of syllables was one or two (Task B).

Each stimulus set (numerical, figural, verbal) consisted of 100 different items for each of the four possible attribute combinations. In the numerical task, for instance, 100 different digit strings were randomly selected for each of the four attribute combinations: (a) larger-equal, (b) largerunequal, (c) smaller-equal, and (d) smaller-unequal. Similarly, 100 different words in each of the four attribute combinations were selected for the verbal task by using CELEX. ${ }^{4}$ These attribute combinations were (a) animate-one syllable, (b) animate-two syllables, (c) inanimate-one syllable, and (d) inanimate-two syllables. For the figural task, the attribute combinations were constructed by combining 10 different colors (red, blue, green, yellow, rose red, orange, light blue, turquoise, brown, violet) and 10 different gray tones (ranging from light gray to black) with 10 different

\footnotetext{
${ }^{4}$ CELEX is a German-word database program developed at the Max Planck Institute in Nijmegen.
} 
triangles and rectangles (side length for each triangle and rectangle were randomly selected), All stimuli were presented successively within a $4 \times$ $5-\mathrm{cm}$ white rectangle in the center of the computer screen. Words were displayed in an uppercase Courier bold 36 font in the center of this array. Digits were presented in Geneva bold 48 font.

\section{Procedure}

The study consisted of eight sessions. In the first session, we tested participants individually. In all other sessions, they were tested and practiced in groups of 1 to 4 . The first three sessions lasted around $90 \mathrm{~min}$, the following four practice sessions took around $45 \mathrm{~min}$, and the posttest assessment lasted $60 \mathrm{~min}$.

In the first session, participants were administered the most part of the cognitive test battery in the following order: Demographic questionnaire, Digit Span, Color-Stroop, Animal Sorting, Spot-a-Word, Figural Analogies, Identical Pictures, Letter Series, Word Span, Position-Stroop, Digit Sorting, Vocabulary, Alpha Sorting, Practical Knowledge, and Visual Span.

The second session started with two paper-pencil tests, the Digit-Symbol and Digit-Letter Substitution Test. Then, participants performed two psychomotor-speed tasks, first Tapping, and then simple reaction time. The main goal of this session was to introduce all six task conditions, Task domain (numerical, figural, verbal) $\times$ RSI $(200 \mathrm{~ms}, 1,200 \mathrm{~ms})$, both under homogeneous and heterogeneous task conditions. The six task conditions were given in the following order to all participants: (a) figural task-long RSI, (b) numerical task-long RSI, (c) verbal task-long RSI, (d) figural task-short RSI, (e) numerical task-short RSI, and (f) verbal task-short RSI. For each task condition, participants first worked through two taskhomogeneous blocks of Task A and then through two task-homogeneous blocks of Task B. Each block always consisted of 16 trials yielding a total of $2 \times 2 \times 16=64$ trials. Task-homogeneous blocks were immediately followed by four corresponding task-heterogeneous blocks. We presented task-homogeneous blocks first to make sure that research participants acquired the relevant stimulus-response mappings within Tasks A and B prior to the measurement of switching performance. Two of the taskheterogeneous blocks started with AABB ..., and two with BBAA .... These blocks also consisted of 16 trials yielding a total of $2 \times 2 \times 16=64$ trials. Overall, 128 trials (64 task-homogeneous trials plus 64 taskheterogeneous trials) for each of the six task conditions were presented, which corresponds to a total of $6 \times 128=768$ trials per session. We administered the same number of blocks and trials in all following six sessions. Each block consisted of an equal number of observations of task (A-B), switch type (switch-nonswitch), response type (left-right), and previous response (left-right).

The third session established the pretest assessment for all six task conditions for task-homogeneous as well as for task-heterogeneous blocks. Prior to the experimental part, participants were given Raven's Advanced Progressive Matrices Test (Raven, Court, \& Raven, 1987). In Sessions 4 to 7 , all six task conditions were practiced. The experimental procedure at posttest was identical to the pretest assessment. At the end of the posttest, we administered the two psychomotor-speed tests, Tapping and simple reaction time, again.

In the four practice sessions, we used complex counterbalancing schemes within and across participants to avoid confounding the effects of stimulus type, task type, and RSI with order effects. In contrast, we administered the pretest and posttest sessions in the same fixed sequence to enhance the assessment of individual differences in general and specific switch costs (Jensen, 1987).

The only difference between task-homogeneous and task-heterogeneous blocks was induced through different task instructions. In taskhomogeneous blocks, we instructed participants to perform only Task A or Task B. In task-heterogeneous blocks (e.g., AABBAABB ... or BBAABBAA ...), we instructed participants to perform Task A (classi- fying figures) twice, then perform Task B (classifying colors) twice, and then to begin either with Task A or with Task B between blocks.

\section{Results}

The findings are presented in two parts. In the first, we conducted analyses of variance (ANOVAs) in order to test agespecific effects in general and specific switch costs as a function of task domain, practice, and RSI. In the second, we used structural modeling approach and correlational analyses to examine relations between cognitive control and intellectual abilities.

\section{Data Analysis}

Given the relatively high power of the present study and the large number of statistical tests, we generally adopted the conservative criterion of an alpha level of .01. We report results of a .05 alpha level insofar as they relate to differences of correlations between switching measures and intellectual measures, because the power for detecting group differences in correlations is lower than the power for detecting group differences in means (Cohen, 1977).

To examine age differences in general and specific switch costs, we specified two orthogonal contrasts (see Table 3). In a first contrast (Trial Type 1), we tested mean latencies of taskhomogeneous trials against mean latencies of task-heterogeneous trials (general switch costs). In a second contrast (Trial Type 2), we tested mean latencies of nonswitch trials against mean latencies of switch trials (specific switch costs). Two orthogonal contrasts were specified for age. The first contrast tested performance of young adults against performance of middle-aged and old adults (Age Contrast 1), and the second contrast tested performance of middle-aged adults against performance of old adults (Age Contrast 2).

In the correlational analyses, we computed costs in agreement with the two orthogonal contrasts, Trial Type 1 and Trial Type 2. Specifically, general switch costs were defined as the differences between mean reaction times in task-heterogeneous blocks minus mean reaction times in task-homogeneous blocks, and specific switch costs as difference scores of mean reaction times in switch trials minus mean reaction times in nonswitch trials within taskheterogeneous blocks.

Dependent variables were generally based on the natural logarithm of reaction times for correct responses. Note that costs were

Table 3

Orthogonal Contrasts Used in Statistical Analysis

\begin{tabular}{|c|c|c|}
\hline Factor-Label & Meaning & $\begin{array}{l}\text { Contrast in } \\
\text { ANOVA }\end{array}$ \\
\hline \multicolumn{3}{|l|}{ Age group (between subjects) } \\
\hline Age Contrast 1 & $\begin{array}{l}\text { Young vs. middle-aged } \\
\text { and old }\end{array}$ & $\begin{array}{lll}-2 & 1 & 1\end{array}$ \\
\hline Age Contrast 2 & Middle-aged vs. old & $0-11$ \\
\hline \multicolumn{3}{|l|}{ Trial Type (within subjects) } \\
\hline 1 & $\begin{array}{l}\text { Homogeneous vs. } \\
\text { nonswitch and switch }\end{array}$ & $\begin{array}{lll}-2 & 1 & 1\end{array}$ \\
\hline 2 & Nonswitch vs. switch & $0-11$ \\
\hline
\end{tabular}

Note. ANOVA $=$ analysis of variance. 
expressed as difference between logarithms, which is equivalent to ratio scores (Ratcliff, 1993). The purpose of this method was to express costs as proportions because ratio scores are generally less sensitive to differences in baseline performance (e.g., overall speed of responding; Meiran, 1996). ${ }^{5}$

Data analyses generally focused on response latencies. In contrast to other studies (see Rogers \& Monsell, 1995), we computed no difference score of errors because of design-based inability to detect $50 \%$ of the errors. Within task-heterogeneous blocks, switching errors (errors due to failure of the reconfiguration process) were confounded with categorization errors (errors due to the incorrect selection of response alternatives within a task set). For this reason, we excluded all task-heterogeneous blocks with three or more than three errors from data analysis. To reduce, on the other hand, the percentage of missing data, task-heterogeneous blocks with one or more than one error were immediately repeated for each of the six task conditions in each session.

Generally, we observed no missing data for young adults but for middle-aged and old adults, primarily in the first experimental sessions (pretest: $4.6 \%$ for middle-aged adults, $9.0 \%$ for old adults; Practice 1: $0.8 \%$ middle-aged adults, $0.4 \%$ for old adults). Missing data were estimated in the following procedure. First, $8.8 \%$ of the missing data were replaced by using regression techniques, in which missing values of a given dependent variable (e.g., numerical task) were predicted from the means of the two nonmissing variables (e.g., figural and verbal task). This was done separately within age groups, RSI, and sessions. Mean reaction times of the dependent variables did not significantly change after missing data replacement. Second, the remaining missing values were replaced with the mean reaction time of the corresponding age group. ${ }^{6}$

\section{Results Part I: Age Differences in General Switch Costs and Specific Switch Costs}

In the beginning of this section, we provide an overview of all observed main effects. Then, we focus on Age $\times$ Treatment interactions following the research predictions laid out in the Introduction. General switch costs (i.e., differences in log latencies between heterogeneous and homogeneous trials) are displayed as a function of age group, task, RSI, and session in Figure 2. Specific switch costs (i.e., differences in log latencies between switch and nonswitch trials) are shown as a function of age group, task, RSI, and session in Figure 3. Tables 4 to 7 display log-transformed latencies at various levels of aggregation to enhance the interpretability of main effects and interactions.

Overview. For an overall analysis, we analyzed $\log$ transformed latencies with a repeated-measure ANOVA with Age Group (young, middle-aged, old) as between-subject factor and Trial Type (homogeneous, nonswitch, switch), Task (numerical, figural, verbal), RSI (200 ms, $1200 \mathrm{~ms}$ ), and Session (pretest, Practice 1 to Practice 4, posttest) as within-subject factors.

In this overall analysis, all main effects were highly significant. We found considerable age differences in latencies between young adults and middle-aged and old adults, $F(1,115)=64.07$, $M S E=3.16, p<.01, \eta^{2}=.36$, and also between middle-aged adults and old aduits, $F(1,115)=18.64, M S E=3.16, p<.01$, $\eta^{2}=.14$. Substantial differences in latencies were also observed between homogeneous, nonswitch, and switch trials (for differences, see next section), $F(1,115)=1285.51, M S E=0.14, p<$
$.01, \eta^{2}=.92$. Furthermore, we observed practice effects, indicating that latencies became significantly shorter with increasing practice, $F(5,575)=387.98, M S E=0.04, p<.01, \eta^{2}=.77$. In addition, we found a highly significant effect of task preparation, $F(1,115)=436.4, M S E=0.028, p<.01, \eta^{2}=.79$, with substantially faster latencies with long RSIs. Finally, there were reliable differences in latencies between numerical, figural, and verbal tasks, $F(1,115)=1951.72, M S E=0.17, p<.01, \eta^{2}=.94$. Bonferroni-adjusted post hoc comparisons based on homogeneous trials, which indicated differences in baseline performances, and contrasts between each of the three task domains revealed that latencies were significantly smaller in figural than in numerical tasks, $F(1,115)=5833.14, M S E=0.01, p<.0033, \eta^{2}=.98$. Latencies were also significantly smaller in figural than in verbal tasks, $F(1,115)=1407.73, M S E=0.0033, p<.01, \eta^{2}=.92$, and furthermore, latencies were significantly smaller in verbal than in numerical tasks, $F(1,115)=1346.32, M S E=0.0033, p<.01$, $\eta^{2}=.92$.

Age differences in general and specific switch costs. Table 4 displays the log-transformed latencies of homogeneous, nonswitch trials, switch trials, general switch costs, and specific switch costs as a function of task domain and age group, collapsed across RSI and sessions. We computed an ANOVA with age group (young, middle-aged, old) as between-subject variable and trial type (homogeneous, nonswitch, switch) as within-subject variable.

Overall, substantial general and specific switch costs were found, Trial Type 1: $F(1,115)=1250.69, M S E=0.05, p<.01$, $\eta^{2}=.92$, Trial Type $2: F(1,115)=903.54, M S E=0.01, p<.01$, $\eta^{2}=.89$. Age differences in task-switching performance were observed only for general switch costs; that is, older adults (middle-aged and old adults) showed greater general switch costs than younger adults, Age Contrast $1 \times$ Trial Type 1: $F(1$, 115) $=28.54, M S E=0.05, p<.01, \eta^{2}=.02$. Furthermore, age differences in general and specific switch costs were absent for the comparison of middle-aged and old adults.

In order to test for differences in the age relations between general and specific task switching, we used Formula 4 in Meng, Rosenthal, and Rubin (1992). With age as a continuous variable, the difference in age relations was reliable at the .01 level $\left(r_{\text {age, general costs }}=.47, r_{\text {age, specific costs }}=.16, r_{\text {general costs, specific costs }}=\right.$ .50 , for difference in age relations, $z=3.56, p<.01$ ).

The generality of age effects in general and specific switch costs. Table 5 shows the relevant log-transformed latencies of homogeneous, nonswitch, and switch trials, and the two costs measures separately for the numerical, figural, and verbal task domain. We computed ANOVAs separately for each of the three task domains (numerical, figural, verbal), because the main interest was to explore the generality of age differences in general and

\footnotetext{
${ }^{5}$ Although the results reported in this article are based on logtransformed reaction times, we added the raw latencies of homogeneous trials, general switch costs, and specific switch costs in the Appendix to provide a comparison of results between studies.

${ }^{6}$ Three of the old adults were not able to accurately perform the experimental tasks at pretest; that is, they had more than three errors within experimental blocks of most task conditions. Within each experimental condition, missing data for these participants were replaced by the mean of their corresponding age groups.
} 

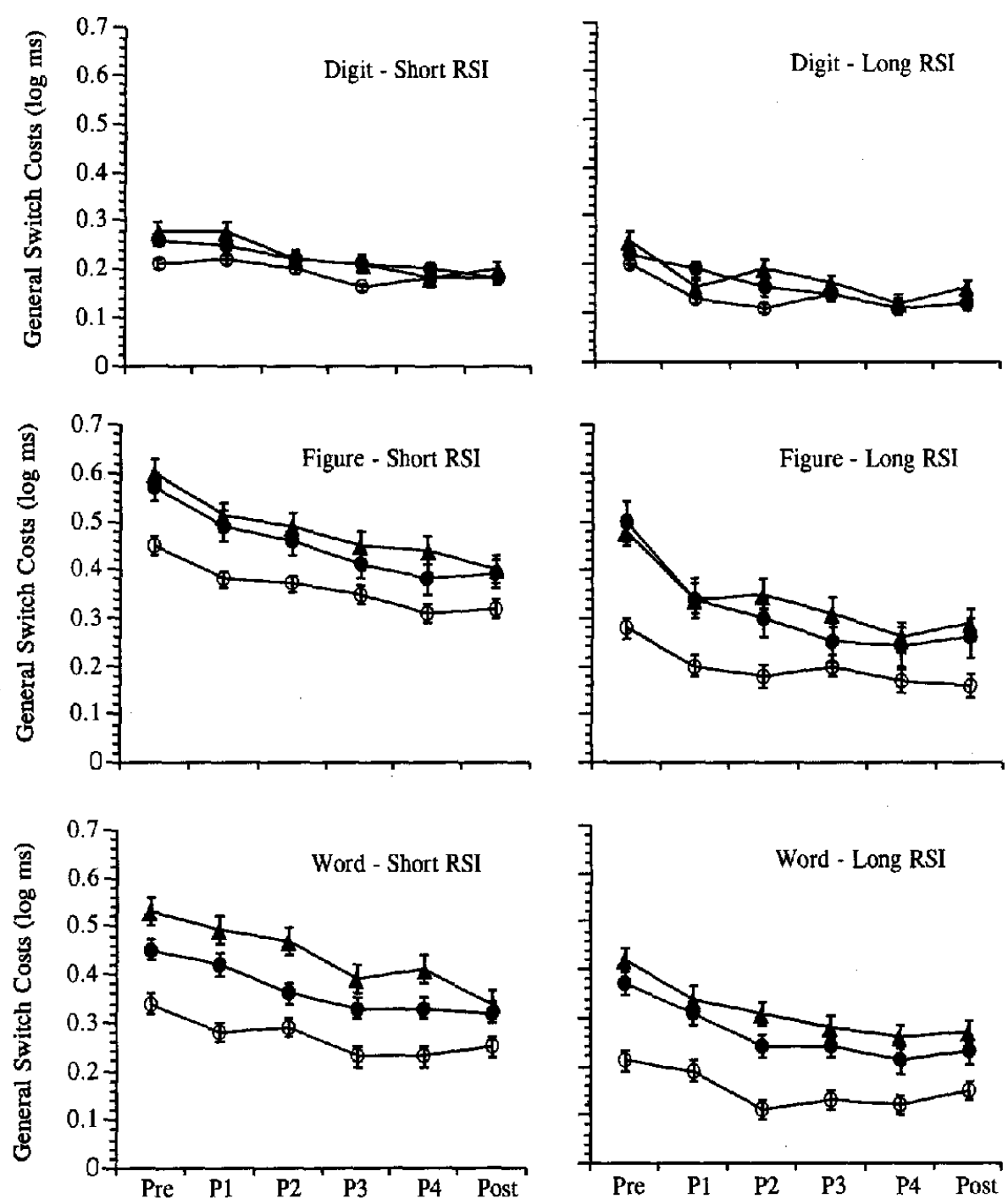

Figure 2. Log-transformed reaction time (RT) and standard errors of general switch costs as a function of task, response stimulus interval (RSI), session, and age group: young (open circles), middle-aged (solid circles), and old (solid triangles).

specific task-switching performance across task domains. Separate analyses ò task domain were also justified by a significant triple interaction of age group, trial type, and task domain in an overall analysis, $F(8,115)=9.13, M S E=0.002, p<.01, \eta^{2}=.04$.

Substantial general and specific switch costs were observed for numerical tasks, Trial Type 1: $F(1,115)=740.25, M S E=0.02$, $p<.01, \eta^{2}=.87$, Trial Type $2: F(1,115)=623.45, M S E=0.01$, $p<.01, \eta^{2}=.85$, for figural tasks: $F(1,115)=1250.69$, $M S E=0.05, p<.01, \eta^{2}=.92$, Trial Type $2: F(1,115)=903.54$, $M S E=0.01, p<.01, \eta^{2}=.89$, and also for verbal tasks: $F(1$, $115)=972.70, M S E=0.05, p<.01, \eta^{2}=.89$, Trial Type $2: F(1$, $115)=717.37, M S E=0.01, p<.01, \eta^{2}=.86$. Thus, general and specific switch costs generalize across task domains.

We observed no significant age differences in general or specific switch costs in numerical task. In figural tasks, middle-aged and old adults showed substantially greater general switch costs than young adults, Age Contrast $1 \times$ Trial Type 1: $F(1$, $115)=28.54, M S E=0.05, p<.01, \eta^{2}=.20$, but age differences in specific switch costs were not reliable. In addition, no significant age differences were found between middle-aged and old adults for either general or specific switch costs. We found a similar pattern of results for verbal tasks. Older adults showed substantially greater general switch costs than young adults, Age Contrast $1 \times$ Trial Type 1: $F(1,115)=43.25, M S E=0.04, p<$ $.01, \eta^{2}=.26$, but age differences for specific switch costs were again not reliable. Moreover, old adults showed greater general switch costs than middle-aged adults, Age Contrast $2 \times$ Trial Type 1: $F(1,115)=6.25, M S E=0.04, p=.0138, \eta^{2}=.04$, but no significant age differences were observed for specific switch costs.

The difference in age relations between general and specific switch costs was statistically reliable for figural tasks $\left(r_{\text {age, general costs }}\right.$ $=.40, r_{\text {age, specific costs }}=.04, r_{\text {general costs, specific costs }}=.41$, for 

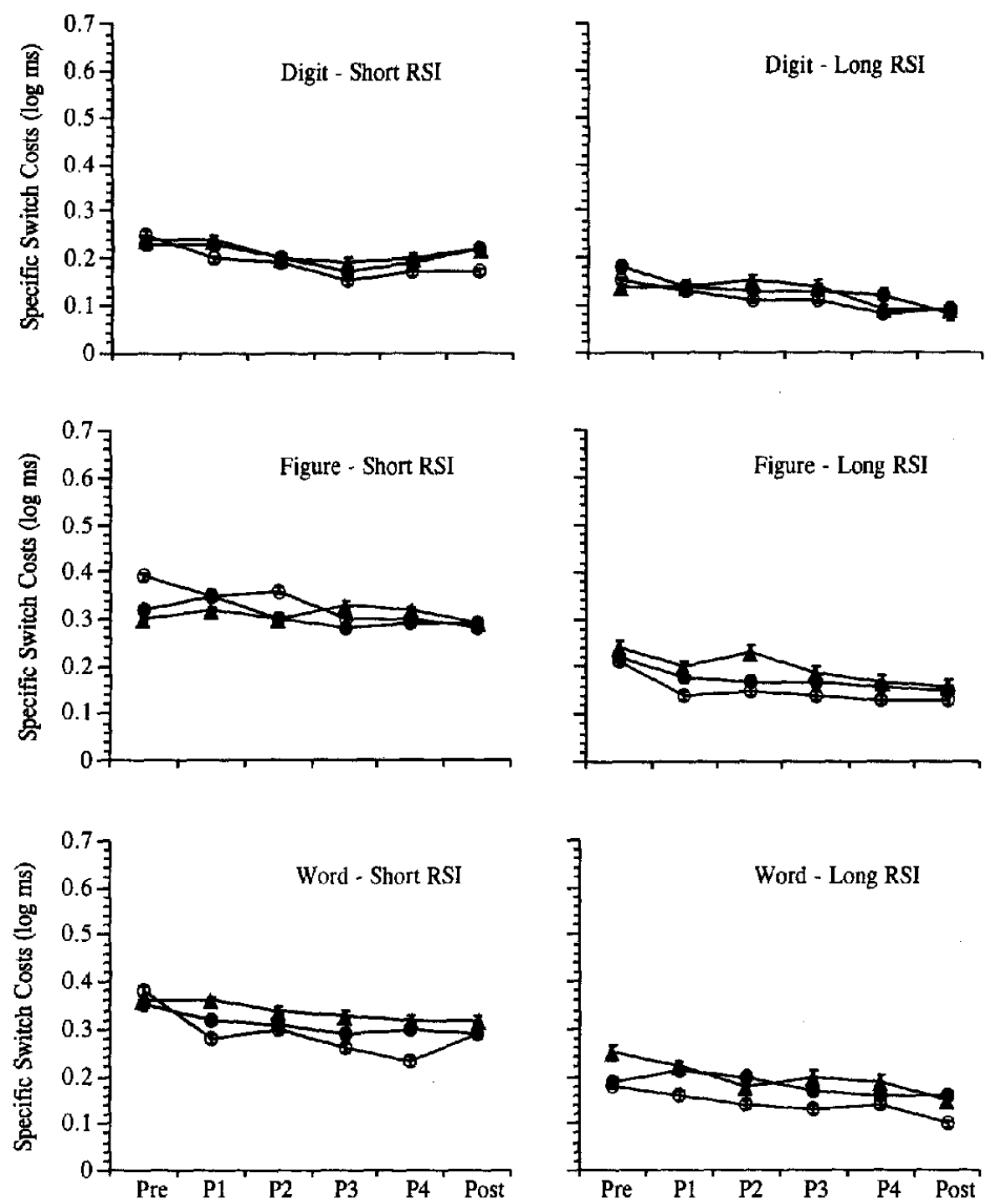

Figure 3. Log-transformed reaction time (RT) and standard errors of specific switch costs as a function of task, response stimulus interval (RSI), session, and age group: young (open circles), middle-aged (solid circles), and old (solid triangles).

difference in age relations, $z=3.68, p<.01$ ) and verbal tasks $\left(r_{\text {uge, general costs }}=.55, r_{\text {age, specific costs }}=.23, r_{\text {general costs, specific cost }}\right.$ $=.52$, for difference in age relations, $z=3.90, p<.01$ ), but not for numerical tasks ( $r_{\text {age, general costs }}=.23, r_{\text {age, specific costs }}=.12$, $r_{\text {general costs, specific costs }}=.47$, for difference in age relations, $z=1.17, p>.01)$.

Age effects in general and specific switching performance after extensive practice. To test age differences in general and specific switch effects as a function of practice, we collapsed mean reaction times at pre- and posttest across task domains and RSI (see Table 6). Then, we analyzed data with an Age Group (3) $\times$ Trial Type (3) $\times$ Practice (2) ANOVA with repeated measures on the second and third factors. The analysis showed a highly significant effect of practice, $F(1,115)=816.61, M S E=0.07, p<.01, \eta^{2}=.88$. General and specific switch costs were significantly reduced with increasing practice, Trial Type $1 \times$ Practice: $F(1,115)=235.77$, $M S E=0.03, p<.01, \eta^{2}=.67$, Trial Type $2 \times$ Practice, $F(1$, $115)=95.08, M S E=0.01, p<.01, \eta^{2}=.45$. Although significant interactions were not found between either contrasts of age group with practice, the third-order interaction of Age Group $1 \times$ Trial Type $1 \times$ Practice was significant, $F(1,115)=11.54$, $M S E=0.03, p<.01, \eta^{2}=.03$, indicating that older adults showed a greater reduction of general switch costs from pretest to posttest than younger adults.

At posttest, highly significant main effects were still found for general switch costs, Trial Type 1: $F(1,115)=887.23$, $M S E=0.03, p<.01, \eta^{2}=.89$, and specific switch costs, Trial Type 2: $F(1,115)=565.06, M S E=0.008, p<.01, \eta^{2}=.83$. The interaction between general switch costs and the contrast of Age Contrast 1 remained also reliable at posttest, Age Contrast $1 \times$ 
Table 4

Means and Standard Deviations of Log-Transformed RTs for (a) Homogeneous, Nonswitch, and Switch Trials and (b) General and Specific Switch Costs Averaged Across

Task, Practice, and RSI

\begin{tabular}{|c|c|c|c|c|c|c|c|c|c|c|}
\hline \multirow[b]{3}{*}{ Group } & \multicolumn{6}{|c|}{ Trial type } & \multicolumn{4}{|c|}{ Costs type } \\
\hline & \multicolumn{2}{|c|}{ Homogeneous } & \multicolumn{2}{|c|}{ Nonswitch } & \multicolumn{2}{|c|}{ Switch } & \multicolumn{2}{|c|}{ General } & \multicolumn{2}{|c|}{ Specific } \\
\hline & $M$ & $S D$ & $M$ & $S D$ & $M$ & $S D$ & $M$ & $S D$ & $M$ & $S D$ \\
\hline Young & 6.35 & 0.15 & 6.47 & 0.18 & 6.67 & 0.24 & 0.218 & 0.026 & 0.201 & 0.029 \\
\hline Middle & 6.49 & 0.13 & 6.67 & 0.18 & 6.89 & 0.21 & 0.295 & 0.029 & 0.219 & 0.022 \\
\hline Old & 6.63 & 0.13 & 6.86 & 0.16 & 7.07 & 0.19 & 0.328 & 0.027 & 0.230 & 0.021 \\
\hline
\end{tabular}

Note. $\quad$ RT $=$ reaction time; RSI $=$ response stimulus interval.

Trial Type 1: $F(1,115)=15.64, M S E=0.03, p<.01, \eta^{2}=.02$. Thus, older adults continued to show larger general switch costs than younger adults after four sessions of practice.

The effects of task preparation. To examine whether age effects in general and specific switch costs varied as a function of RSI, we computed an Age Group (3) $\times$ Trial Type (3) $\times$ RSI (2) ANOVA with repeated measures on the second and third factors (see Table 7). General and specific switch costs were smaller with long RSIs, Trial Type $1 \times$ RSI: $F(1,115)=429,12, M S E=0.01$, $p<.01, \eta^{2}=.79$; Trial Type $2 \times$ RSI: $F(1,115)=362.44$, $M S E=0.01, p<.01, \eta^{2}=.76$. Significant interactions of both age group contrasts with general and specific switch costs and RSI were absent.

Post hoc comparisons revealed that switch costs did not disappear with long RSIs, Trial Type 1: $F(1,115)={ }^{*} 715.35$, $M S E=0.03, p<.01, \eta^{2}=.86$, and Trial Type $2: F(1,115)=$ 559.71, $M S E=0.005, p<.01, \eta^{2}=.83$. Again, the interaction effect between general switch costs and the contrast of Age Con- trast 1 remained reliable for long RSIs, Age Contrast $1 \times$ Trial Type 1: $F(1,115)=31.15, M S E=0.03, p<.01, \eta^{2}=.04$.

Discussion. The results of the preceding analyses suggested that young adults have smaller general switch costs than middleaged and old adults. Thus, young adults were more efficient than middle-aged and old adults in maintaining and coordinating two different task sets instead of one. In contrast, young and middleaged and old adults did not differ in specific task switching, that is, in reconfiguring the cognitive system from one task to the next within task-heterogeneous blocks. Two findings are noteworthy: First, substantial general and specific switch costs seem to be very robust phenomena because they were found in all three task domains, after extensive practice, and also with long RSIs. Second, age differences in general switch costs were significantly more pronounced than age differences in specific switch costs. This pattern of results generalized over two of the three task domains.

Although we found reliable general and specific switch costs in the numerical task domain, neither of these costs interacted with

Table 5

Means and Standard Deviations of Log-Transformed RTs for (a) Homogeneous, Nonswitch, and Switch Trials and (b) General and Specific Switch Costs Averaged Across Practice and RSI

\begin{tabular}{|c|c|c|c|c|c|c|c|c|c|c|}
\hline \multirow[b]{3}{*}{ Group } & \multicolumn{6}{|c|}{ Trial type } & \multicolumn{4}{|c|}{ Costs type } \\
\hline & \multicolumn{2}{|c|}{ Homogeneous } & \multicolumn{2}{|c|}{ Nonswitch } & \multicolumn{2}{|c|}{ Switch } & \multicolumn{2}{|c|}{ General } & \multicolumn{2}{|c|}{ Specific } \\
\hline & $M$ & $S D$ & $M$ & $S D$ & $M$ & $S D$ & $M$ & $S D$ & $M$ & $S D$ \\
\hline \multicolumn{11}{|c|}{ Numerical task } \\
\hline Young & 6.66 & 0.18 & 6.75 & 0.20 & 6.90 & 0.24 & 0.162 & 0.069 & 0.151 & 0.078 \\
\hline Middle & 6.84 & 0.16 & 6.94 & 0.18 & 7.11 & 0.21 & 0.187 & 0.071 & 0.169 & 0.072 \\
\hline Old & 7.00 & 0.14 & 7.12 & 0.16 & 7.29 & 0.17 & 0.198 & 0.075 & 0.169 & 0.062 \\
\hline \multicolumn{11}{|c|}{ Figural task } \\
\hline Young & 6.00 & 0.13 & 6.16 & 0.18 & 6.40 & 0.23 & 0.281 & 0.106 & 0.240 & 0.102 \\
\hline Middle & 6.14 & 0.13 & 6.40 & 0.19 & 6.64 & 0.23 & 0.382 & 0.119 & 0.240 & 0.079 \\
\hline old & 6.31 & 0.18 & 6.59 & 0.19 & 6.85 & 0.21 & 0.410 & 0.105 & 0.254 & 0.083 \\
\hline \multicolumn{11}{|c|}{ Verbal task } \\
\hline Young & 6.39 & 0.18 & 6.49 & 0.19 & 6.71 & 0.26 & 0.211 & 0.093 & 0.213 & 0.111 \\
\hline Middle & 6.48 & 0.15 & 6.67 & 0.18 & 6.92 & 0.25 & 0.317 & 0.101 & 0.247 & 0.098 \\
\hline Old & 6.57 & 0.13 & 6.82 & 0.18 & 7.08 & 0.22 & 0.376 & 0.120 & 0.267 & 0.083 \\
\hline
\end{tabular}

Note. $\quad \mathrm{RT}=$ reaction time; $\mathrm{RSI}=$ response stimulus interval. 
Table 6

Means and Standard Deviations of Log-Transformed RTs for (a) Homogeneous, Nonswitch, and Switch Trials and (b) General and Specific Switch Costs as a Function of Practice Averaged Across Task Domain and RSI

\begin{tabular}{|c|c|c|c|c|c|c|c|c|c|c|}
\hline \multirow[b]{3}{*}{ Group } & \multicolumn{6}{|c|}{ Trial type } & \multicolumn{4}{|c|}{ Costs type } \\
\hline & \multicolumn{2}{|c|}{ Homogeneous } & \multicolumn{2}{|c|}{ Nonswitch } & \multicolumn{2}{|c|}{ Switch } & \multicolumn{2}{|c|}{ General } & \multicolumn{2}{|c|}{ Specific } \\
\hline & $M$ & $S D$ & $M$ & $S D$ & $M$ & $S D$ & $M$ & $S D$ & $M$ & $S D$ \\
\hline \multicolumn{11}{|c|}{ Pretest } \\
\hline Young & 6.43 & 0.16 & 6.58 & 0.20 & 6.84 & 0.25 & 0.282 & 0.102 & .0 .259 & 0.095 \\
\hline Middle & 6.56 & 0.16 & 6.84 & 0.22 & 7.09 & 0.24 & 0.394 & 0.128 & 0.248 & 0.065 \\
\hline Old & 6.69 & 0.14 & 6.99 & 0.20 & 7.24 & 0.22 & 0.425 & 0.129 & 0.255 & 0.081 \\
\hline \multicolumn{11}{|c|}{ Posttest } \\
\hline Young & 6.28 & 0.15 & 6.38 & 0.19 & 6.56 & 0.25 & 0.195 & 0.099 & 0.176 & 0.100 \\
\hline Middle & 6.41 & 0.12 & 6.56 & 0.17 & 6.76 & 0.20 & 0.249 & 0.085 & 0.198 & 0.085 \\
\hline Old & 6.56 & 0.13 & 6.74 & 0.16 & 6.94 & 0.19 & 0.275 & 0.078 & 0.204 & 0.075 \\
\hline
\end{tabular}

Note. $\quad \mathrm{RT}=$ reaction time; $\mathrm{RSI}=$ response stimulus interval.

age. In retrospect, this absence of reliable age differences in numeric shift costs seems consistent with the more general phenomenon that adult age differences in simple arithmetic as well as in other tasks in the numerical domain tend to be relatively small compared with other domains (Geary \& Wiley, 1991; Sliwinski, Buschke, Kuslansky, Senior, \& Scarisbrick, 1994; Verhaeghen, Kliegl, \& Mayr, 1997), perhaps as a consequence of lifelong practice or cohort effects (cf. Schaie, 1996). However, a similar argument could be made with respect to the verbal task domain, which did show significant age differences in general switch costs. Future attempts at clarifying this issue need to closely examine the processing mechanisms involved in maintaining, coordinating, and shifting between the two tasks of each of the three domains.

We also observed substantial age differences in general but not in specific task-switching performance at posttest and with long RSIs. These findings are constrained by the fact that additional analyses revealed a significant reduction of response latencies from the third to the last practice session for both nonswitch and switch trials and, especially, for middle-aged and old adults. ${ }^{7}$ Thus, when interpreting age differences in practice effects and final levels of performance, one needs to keep in mind that asymptotic levels of performance were approximated but not reached in the course of this experiment.

The results also showed that there were large gains of performance in all three age groups during the practice sessions (see also Kramer et al., 1999) and for long RSIs. Thus, results of this study suggested that younger and older adults were able to profit from easier constraints during task switching.

Taken together, the source of age differences in task switching is primarily related to the ability of organizing cognitive processing in a dual-task-like situation; that is, older adults were specifically impaired in working memory abilities such as keeping task instructions online and keeping track of the task sequence while switching between tasks. In contrast, young and old adults showed proportional increments in latency of similar magnitude when switching from one task set to the other. The reduction of general and specific switch costs with increasing practice and with long
RSIs suggests a positive amount of modifiability in cognitive control performance in both young and old adults.

\section{Part II: Relations Between Cognitive Control and Intellectual Abilities}

The major goals in the second set of analyses were to examine (a) whether the two components of cognitive control formed distinct factors, (b) whether the structure of intellectual and psychomotor-speed abilities could be represented using confirmatory factor analysis, (c) whether both cognitive control components were more highly correlated to measures from the broad fluid intelligence domain than to measures from the crystallized intelligence domain, and (d) whether the intercorrelations between cognitive control components and intellectual abilities differed as a function of age.

Ability structures were tested by confirmatory factor analysis using structural modeling (EQS; Bentler, 1989). The main advantages of the structural equation modeling approach are (a) that intercorrelations between constructs at the latent level are cor-

\footnotetext{
${ }^{7}$ To test to what extent asymptotic levels of performance were approximated during the practice phase, we compared log-transformed reaction times of each dependent variable between the third and last practice session (separately for each experimental condition and age group). In taskhomogeneous blocks, no significant reductions in response latencies between practice Sessions 3 and 4 were found. For the nonswitch trials within task-heterogeneous blocks, a significant decrease of latencies was observed in four conditions-middle aged: digit-short RSI: $t(39)=2.79, p<.01$, old adults: digit-short RSI: $t(38)>4.4, p<.01$, young: figure-short RSI: $t(38)=3.54, p<.01$, middle-aged: word-short RSI: $t(39)>3.39, p<.01$. In addition, a significant decrease of latencies in switch trials was also found in four conditions-old: digit-short: $t(38)>2.93, p<.01$, young: digit-long: $t(38)>4.07, p<.01$, old: digit-long: $t(38)>2.78, p<.01$, young: figure short: $t(38)>2.83, p<.01$. Thus, in the more difficult task-heterogeneous trials, asymptotic levels of performance were not reached in all conditions.
} 
Table 7

Means and Standard Deviations of Log-Transformed RTs for (a) Homogeneous, Nonswitch, and Switch Trials and (b) General and Specific Switch Costs as a Function of RSI Averaged Across Task Domain and Practice

\begin{tabular}{|c|c|c|c|c|c|c|c|c|c|c|}
\hline \multirow[b]{3}{*}{ Group } & \multicolumn{6}{|c|}{ Trial type } & \multicolumn{4}{|c|}{ Costs type } \\
\hline & \multicolumn{2}{|c|}{ Homogeneous } & \multicolumn{2}{|c|}{ Nonswitch } & \multicolumn{2}{|c|}{ Switch } & \multicolumn{2}{|c|}{ General } & \multicolumn{2}{|c|}{ Specific } \\
\hline & $M$ & $S D$ & $M$ & $S D$ & $M$ & $S D$ & $M$ & $S O$ & $M$ & $S D$ \\
\hline \multicolumn{11}{|c|}{ RSI $(200 \mathrm{~ms})$} \\
\hline Young & 6.37 & 0.15 & 6.51 & 0.18 & 6.78 & 0.23 & 0.276 & 0.079 & 0.269 & 0.105 \\
\hline Middle & 6.51 & 0.14 & 6.71 & 0.18 & 6.99 & 0.22 & 0.348 & 0.090 & 0.275 & 0.082 \\
\hline Old & 6.65 & 0.13 & 6.89 & 0.17 & 7.17 & 0.19 & 0.382 & 0.091 & 0.288 & 0.084 \\
\hline \multicolumn{11}{|c|}{ RSI $(1,200 \mathrm{~ms})$} \\
\hline Young & 6.33 & 0.16 & 6.43 & 0.20 & 6.56 & 0.26 & 0.160 & 0.088 & 0.134 & 0.088 \\
\hline Middle & 6.46 & 0.13 & 6.63 & 0.18 & 6.79 & 0.22 & 0.245 & 0.096 & 0.162 & 0.067 \\
\hline Old & 6.61 & 0.13 & 6.80 & 0.17 & 6.97 & 0.19 & 0.273 & 0.088 & 0.172 & 0.057 \\
\hline
\end{tabular}

Note. $\quad \mathrm{RT}=$ reaction time; $\mathrm{RSI}=$ response stimulus interval.

rected for measurement errors and (b) that the magnitude of age-based differences in ability structures can be tested by constraining, in a stepwise fashion, different aspects of the measurement models (factor loadings, residuals, factor variances) to be equal across age groups. To enhance the statistical power for rejecting measurement equivalence across groups, we used a twogroup, rather than three-group, age split to examine age differences in ability structures. In addition, we also investigated whether theoretically reasonable alternative models were equally consistent with the data. Model fitting was based on variance-covariances matrices of intellectual ability and cognitive control measures. Prior to model fitting, we inspected all raw data for deviations from multivariate normality assumptions. For all variables, kurtosis and skewness ranged between +1 and -1 . The normalized estimate of Mardia's coefficient of multivariate kurtosis was 0.84 . As goodness of fit indexes, we used the comparative fit index (CFI) and the non-normed fit index (NNFI).

The structure of cognitive control. The specific question was whether it is possible to separate two interrelated factors of cognitive control at the latent level. Indicators of cognitive control ability were general and specific switch costs, measured within three different task domains and aggregated across RSI and sessions. ${ }^{8}$ To test the factor structure of cognitive control abilities, a first model was specified with two first-order factors that were allowed to covary freely (see Figure 4). Specifically, costs of general switching ability were indicated by general switch costs of the digit (DGC), figure (FGC), and word (WGC) tasks. Costs of specific switch ability were indicated by specific switch costs of the digit (DSC), figure (FSC), and word (WGC) tasks. No restrictions were imposed on variances among factors, and residual variances of the three indicators were freely estimated. An inspection of fit indexes revealed that this model did not yield a satisfactory account of the data, $\chi^{2}(8, N=118)=45.49$, $\mathrm{NNFI}=0.819, \mathrm{CFI}=0.904$. After inspecting the standardized residual covariance matrix, three residual covariances of indicators from the same task domain (numerical, figural, verbal) were allowed to be freely estimated. As a consequence, the fit indexes of the model increased considerably, $\chi^{2}(5, N=118)=16.08$, $\mathrm{NNFI}=0.914, \mathrm{CFI}=0.971$. The increment in fit was significant, $\Delta \chi^{2}(3, N=118)=29.41, p<.01$. Given the satisfactory magnitude of its fit indexes, this model was retained as adequate.

We also examined whether a single factor model would adequately represent the data. The fit indexes of this alternative model clearly showed that this model did not reproduce the data appropriately, $\chi^{2}(9, N=118)=120.11, \mathrm{NNFI}=0.523, \mathrm{CFI}=0.714$ Thus, results of confirmatory factor analysis showed that a model with two latent factors representing general and specific task switching was more adequate than a single-factor model. At the same time, residual covariances were needed in the two-factor model to account for domain variance across the two types of switching (see Figure 4).

In the next step, we set up the accepted measurement model as a two-group model comparing younger $\left(n_{1}=59\right.$; age range: 20-50 years) and older ( $n_{2}=59$; age range: $51-80$ years) adults, and found it to yield a satisfactory representation of the data structure, $\chi^{2}\left(10, n_{1}=59, n_{2}=59\right)=12.72$, NNFI $=0.978$, CFI $=0.993$. Next, we constrained all factor loadings, residuals, residual covariances, and factor variances to be equal across groups, $\chi^{2}\left(25, n_{1}=59, n_{2}=59\right)=25.68$, NNFI $=0.998$, $\mathrm{CFI}=0.998$, without resulting in a significant decrement in fit, $\Delta \chi^{2}\left(15, n_{1}=59, n_{2}=59\right)=12.96, p>.01$. These results suggest metric invariance of the measurement model (Meredith, 1993) between age groups, which implies equality of the factor structure of general and specific aspects of task switching when comparing young and old adults. Within the logic of the common-factor

\footnotetext{
${ }^{8}$ The inspection of relations between intellectual ability composites and the two components of cognitive control-general and specific switch costs-revealed that these relations did not vary considerably as a function of practice and RSI. Therefore, general and specific switch costs of all experimental conditions were aggregated into a single composite measurement to enhance reliability (Rushton, Brainerd, \& Pressley, 1983).
} 


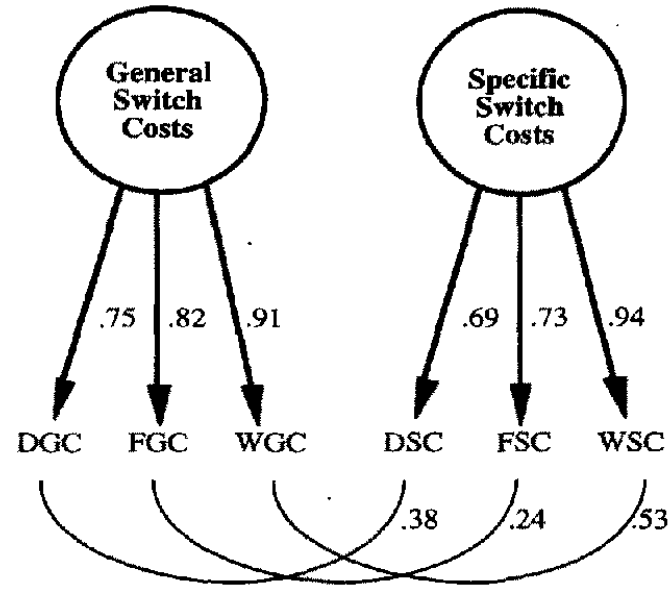

Figure 4. The accepted measurement model of cognitive control, $x^{2}(5$, $N=118)=16.08$, non-normed fit index $=.914$, comparative fit index $=$ 971. DGC $=$ general switch costs of the numerical task; FGC $=$ general switch costs of the figural task; WGC = general switch costs of the verbal task; DSC = specific switch costs of the numerical task; FSC = specific switch costs of the figural task; WSC = specific switch costs of the verbal task.

model, this also implies that the reliability of the measures did not differ by age groups.

The structure of intellectual abilities. Before relating cognitive control to intellectual abilities, we examined the structural properties of the measures representing the intellectual domain. Overall, we used 17 psychometric tests to measure six intellectual abilities: Reasoning was indicated by Raven (RAV), Figural Analogies (FA), and Letter Series (LS); perceptual speed was indicated by Digit-Symbol Test (DS), Digit-Letter Test (DL), and Identical Pictures (IP); primary memory was indicated by Visual Span (FSp), Digit Span (DSp), and Word Span (WSp); working memory was indicated by Sort Digit Span (SDSp), Sort Word Span (SWSp), and Sort Animal Span (SASp); knowledge was indicated by Vocabulary (VC), Practical Knowledge (PW), and Spot-aWord (SW); and, finally, inhibition was indicated by Color-Stroop (CSTr) and Position-Stroop (PSTr). First, a six first-order factor structure (MI1) was specified. Latent factors were again allowed to covary freely. Unfortunately, the fit statistics indicated a relatively poor fit of the model, $\chi^{2}(104, N=118)=171.39$, NNFI $=0.872$, $\mathrm{CFI}=0.902$. The inspection of the standardized covariance matrix of the 17 measures showed that the two indicators of interference were less highly correlated to each other $(r=.16)$ than they were related to other parts of the measurement space (e.g., the median correlation with the reasoning measures was $r=-.43$ for ColorStroop and $r=-.21$ for Position-Stroop). Therefore, we decided to drop the interference measures from the analysis (see Park, Lautenschlager, Smith, \& Earles, 1996, for a similar situation). Furthermore, two residual covariances were allowed to be freely estimated, Digit Letter and Digit Symbol; and Identical Pictures and Visual Span. The resulting five-factor model (see Figure 5) showed satisfactory fit indexes, $\chi^{2}(78, N=118)=117.29$, NNFI $=0.918$, CFI $=0.939$.

We also computed an alternative model by specifying a threefactor structure with the constructs of memory (six memory tests), fluid intelligence (perceptual speed and reasoning tests), and knowledge, $\chi^{2}(87, N=118)=250.23, \mathrm{NNFI}=0.694$, $\mathrm{CFI}=0.746$. Compared with the model described before, this alternative model showed a significant decrement in fit, $\Delta \chi^{2}(5$, $N=118)=132.94, p<.01$. Figure 5 displays the accepted five-factor model.

In the next step, we set up the accepted model as a two age-group model ( $n_{1}=59$; age range: $20-50$ years; $n_{2}=59$; age range: $51-80$ years) with satisfactory fit indexes, $\chi^{2}\left(156, n_{1}=59\right.$, $n_{2}=59$ ) $=172.21$, NNFI $=0.953$, CFI $=0.965$. Then, we constrained all factor loadings, residuals, residual covariances, and factor variances to be equal across groups. This did not result in a significant loss in fit, $\Delta \chi^{2}\left(5, n_{1}=59, n_{2}=59\right)=8.66, p>.01$, suggesting that the structure of intellectual abilities was invariant across the two age groups.

To summarize, our analyses indicate that the assumption of metric invariance across age groups can be retained with respect to the measurement models of intellectual and cognitive control abilities. Thus, we are now in a position to examine construct relations at the latent level as well as age-group differences in these relations.

Intercorrelated ability structure. The focus in this section was on examining whether the two cognitive control components were more highly correlated to measures from the broad fluid intelligence domain than to measures from the crystallized domain. The two acceptable measurement models were not combined into an overall measurement model because of the large number of parameters to be estimated in combination of small sample sizes. Instead, the intercorrelations between intellectual and switching abilities in Tables 8 and 9 were based on unit-weighted composites. Intercorrelations for the total sample are reported in Table 8.

Total sample. Correlations of general and specific switch costs were significantly higher to reasoning than to knowledge (for general switch costs, $z=-3.85, p<.01$, and for specific switch costs, $z=-2.27, p<.05$ ), and to perceptual speed than to knowledge (for general switch costs, $z=-4.65, p<.01$, and for specific switch costs, $z=-2.32, p<.05$ ). Thus, two typical marker abilities from the broad fluid domain, reasoning and perceptual speed, were more highly related to both types of switch costs than knowledge, a typical marker ability from the broad crystallized domain.

Age-group comparisons. The third aim in this section was to explore whether intercorrelations between cognitive control components and intellectual abilities differed as a function of age. In Table 9, intercorrelations among constructs are shown separately for the younger and older subsamples.

Four findings were noteworthy: First, the differential relations of general and specific switch costs to reasoning versus knowledge observed in the total sample were also observed in the younger subsample (for general switch costs, $z=-2.39, p<.05$, and for specific switch costs, $z=-3.78, p<.01)$ but not in the older subsample (for general switch costs, $z=-0.54, p>.05$, and for specific switch costs, $z=-0.30, p>.05$ ). Furthermore, general and specific switch costs were more negatively related to perceptual speed than to knowledge in the younger subsample (for general switch costs, $z=-2.87, p<.01$, and for specific switch costs, $z=-3.81, p<.01$ ) but not in the older subsample (for general switch costs, $z=-0.47, p>.05$, and for specific switch costs, $z=0.30, p>.05$ ). 


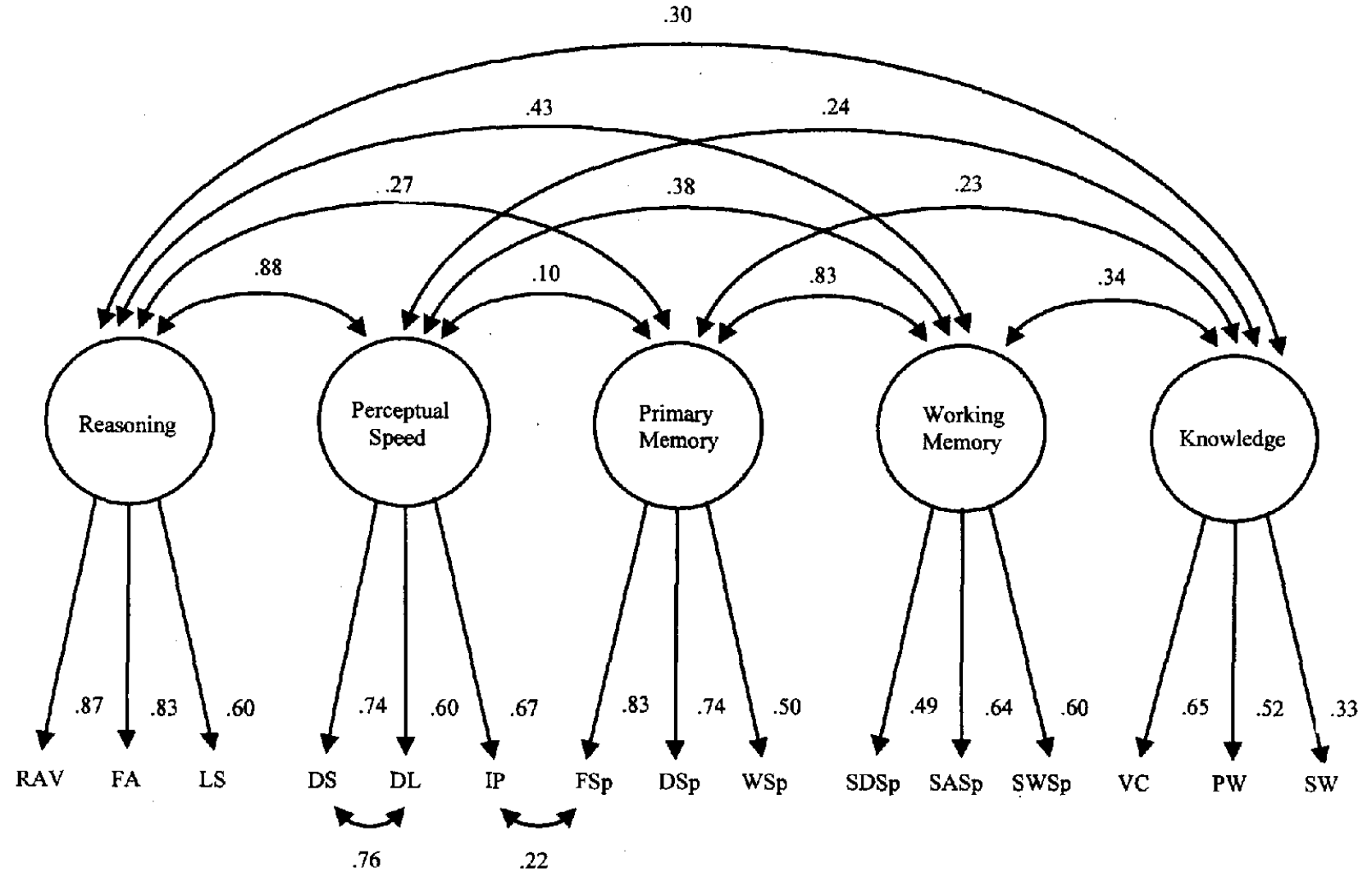

Figure 5. The accepted measurement model of intellectual abilities, $\chi^{2}(78, N=118)=117.29$, non-normed fit index $=.918$, comparative fit index $=.939$. RAV $=$ Raven; FA = Figural Analogies; LS = Letter Series; DS = Digit-Symbol Test; DL = Digit-Letter Test; IP = Identical Pictures; FSp = Visual Span; DSp = Digit Span; $\mathbf{W S p}=$ Word Span; SDSp = Sort Digit Span; SASp = Sort Animal Span, SWSp = Sort Word Span; $\mathrm{VC}=$ Vocabulary; $\mathrm{PW}=$ Practical Knowledge; $\mathrm{SW}=$ Spot-a-Word.

Second, as a general tendency, the correlations of the five intellectual abilities to general and specific switch costs differed among each other in the younger subsample-for general switch costs, $\chi^{2}(d f=4)=18.08, p<.01$, for specific switch costs, $\chi^{2}(d f=4)=14.02, p<.01$, but they did not differ among each other in the older subsample-for general switch costs, $\chi^{2}(d f=$ 4) $=0.32, p>.01$, for specific switch costs, $\chi^{2}(d f=4)=6.04$, $p>.01$. Thus, the relationship between intellectual abilities and cognitive control abilities was less differentiated among older adults than among younger adults.

Third, general switch costs and perceptual speed were more highly correlated among younger adults than among older adults $(z=-2.62, p<.01)$. The same was true for specific switch costs $(z=-2.87, p<.01)$.

Finally, it appeared that working memory occupied a more central role in the intercorrelated factor space among older adults

Table 8

Construct Relations for Total Sample

\begin{tabular}{lccccccc}
\hline \multicolumn{1}{c}{ Variable } & 1 & 2 & 3 & 4 & 5 & 6 & 7 \\
\hline 1. Reasoning & - & $.63^{*}$ & $.26^{*}$ & $.29^{*}$ & $.34^{*}$ & $-.46^{*}$ & $-.32^{*}$ \\
2. Perceptual speed & & - & .10 & .13 & $.26^{*}$ & $-.57^{*}$ & $-.35^{*}$ \\
3. Knowledge & & & - & .20 & .23 & -.04 & -.07 \\
4. Primary memory & & & & - & $.56^{*}$ & -.16 & -.18 \\
5. Working memory & & & & & - & -.19 & $-.25^{*}$ \\
6. General switch costs & & & & & & - & $-.50^{*}$ \\
7. Specific switch costs & & & & & & & - \\
\hline
\end{tabular}

Note. $N=118$

$*_{p}<.01$. 
Table 9

Construct Relations for the Younger and Older Subsamples

\begin{tabular}{llllllll}
\hline \multicolumn{1}{c}{ Variable } & 1 & 2 & 3 & 4 & 5 & 6 & 7 \\
\hline 1. Reasoning & - & $.41^{*}$ & $.50^{*}$ & .25 & .31 & -.23 & -.26 \\
2. Perceptual speed & $.41^{*}$ & - & .22 & .13 & .23 & -.21 & -.15 \\
3. Knowledge & .32 & .19 & - & .17 & .31 & -.16 & -.20 \\
4. Primary memory & $.39^{*}$ & .13 & .24 & - & $.57^{*}$ & -.23 & -.28 \\
5. Working memory & .28 & .16 & .21 & $.56^{*}$ & - & -.27 & -.27 \\
6. General switch costs & $-.39^{*}$ & $-.61^{*}$ & -.03 & -.09 & -.01 & - & $.46^{*}$ \\
7. Specific switch costs & $-.44^{*}$ & $-.60^{*}$ & -.01 & -.10 & -.22 & $.58^{*}$ & - \\
\hline
\end{tabular}

Note. $\quad N=59$. Correlations for the older subsample are shown above the main diagonal, and correlations for the younger subsample are shown below the main diagonal.

$* p<.01$.

than it did among younger adults. Relations of working memory to general switch costs and to specific switch costs seemed to be more negative among older than among younger adults. However, the corresponding statistical tests revealed that these differences were not significant.

Discussion. In this section we examined relations of cognitive control components to intellectual abilities and explored age differences in these relations. The most important finding was that general and specific switch costs are adequately represented by two separate latent factors. Thus, general and specific switch costs can be reliably identified as distinct and domain-general aspects of cognitive control.

Results for the total sample and the younger subsample confirmed the expectation that cognitive control abilities were more closely related to fluid abilities than to crystallized ones (see Salthouse et al., 1998, for specific task switching). However, age-comparative analyses based on metrically invariant measurement models revealed that the correlational dissociation was absent among older adults. Instead, relations of general and specific switch costs to intellectual abilities were more uniform (e.g., less differentiated) in the older subsample. These results seem to be consistent with the theoretical view that cognitive aging is associated with a dedifferentiation of individual differences in intellectual functioning (Baltes, Comelius, Spiro, Nesselroade, \& Willis, 1980; Reinert, 1970; Schaie, Maitland, Willis, \& Intieri, 1998). At the same time, a second criterion for dedifferentiation is that ability intercorrelations are generally more uniform and higher in the old-adults subsample (Lindenberger \& Baltes, 1997). In this study, the median correlations for the younger and the older subsamples did not significantly differ from each other (for the younger subsample: median correlation $=.24$, minimum correlation $=.01$, maximum correlation $=.61$; for the older subsample: median correlation $=.25 ;$ minimum correlation $=.13$, maximum correlation $=.50 ;$ for the difference between the two median correlations: $z=-0.06, p>.05$ ).

Our findings fall well within the range of results reported in a meta-analytic investigation by Verhaeghen and Salthouse (1997), in which intercorrelations and age relations of intellectual abilities were compared between subsamples under and over 50 years of age across multiple studies. In contrast, there is evidence suggesting a dramatic increase in the magnitude of factor intercorrelations with age (e.g., Baltes \& Lindenberger, 1997), but these results were based on an old-adult sample with a mean age of 85 years and an age range between 70 and 103 years. Thus, one possible reason for the present lack of substantial age-group differences in the magnitude of factor intercorrelations could be the relatively low mean age of the older sample.

\section{General Discussion}

The major finding of the present study is that the ability to effectively maintain and coordinate two task sets during task switching is disproportionately impaired with advancing age. In contrast, the ability to reconfigure the cognitive system when switching from one task set to another does not seem to undergo disproportional decline. This function-specific age-based limitation in cognitive control generalized across two of three task domains, and was robust against large amounts of practice and long RSIs. Our findings are in line with evidence that age-based limitations in managing multiple task sets persists even after extensive practice (e.g., Kramer et al., 1995) and that age-based limitations in specific task-switching abilities are often small or absent (Kramer et al., 1999; Mayr \& Liebscher, 1998; Salthouse et al., 1998). In most of these studies, age differences in specific task switching were only found when analyses were based on raw rather than log-transformed latencies, that is, when age differences in baseline performance, or "general slowing," were not taken into account.

Consistent with the theoretical framework of the present study (Baltes et al., 1999; Duncan, 1995, Jersild, 1927; Salthouse et al., 1998; Schaie et al, 1991), significant relations were found between cognitive control and standard measures of intellectual abilities, and in particular with fluid mechanic abilities. The view that general and specific task-switching performances reflect, at least to some extent, mechanic components of the cognitive system was further confirmed by their robustness against large amounts of practice and increased preparation time.

\section{The Relationship Between General Slowness and Difference Scores}

Cognitive aging researchers need to deal with the methodological problem that chronological age cannot be randomly assigned to individuals (Baltes, Reese, \& Nesselroade, 1988; Lindenberger \& Pötter, 1998). With respect to age-comparative studies based on 
latency data, this quasi-experimental character of cognitive aging research is particularly problematic if baseline performance and the magnitude of treatment effects show a strong positive association (Cerella, Poon, \& Williams, 1980; Chapman, Chapman, Curran, \& Miller, 1994; Kliegl, Mayr, \& Krampe, 1994). Specifically, older adults respond more slowly than younger adults, and the magnitude of this difference often increases with task difficulty. This observation has led to the development of statistical techniques that try to assess whether a given Age $\times$ Treatment interaction deviates from what is expected on the basis of "general slowing" (Salthouse, 1988).

In the present study, we addressed this problem by performing all statistical analyses on log-transformed reaction times. The most important advantage of using logarithmic transformations of raw latencies is that differences between logarithms correspond to ratio scores (Ratcliff, 1993). The present finding of function-specific processing differences between young and old adults in the domain of cognitive control is in line with other evidence based on ratio scores (Ferraro \& Moody, 1996; Lima, Hale, \& Myerson, 1991; Mayr \& Kliegl, 1993; Mayr, Kliegl, \& Krampe, 1996). However, most of the earlier findings regarding process-specific slowing were limited to a certain task domain (such as figural transformations; Mayr \& Kliegl, 1993). One important new finding of the present study was to demonstrate process-specific control limitations in old age in two of three task domains. Results of this study suggest that control processes associated with general and specific switch costs are, in fact, general components of the cognitive system, which cannot be overcome by extensive practice and long preparation time and are differently affected by advancing age.

\section{Mediator Models of Age Differences in Cognitive Control}

On the basis of a mediator model with age as the independent variable, perceptual speed as the mediator, and specific task switching as the dependent variable (DV), Salthouse et al. (1998) recently argued that measures of perceptual speed seem to assess more fundamental aspects of cognitive aging than measures of specific task switching. Given that the present study also included measures of perceptual speed, one may wonder why we did not analyze the present data set in similar ways (e.g., by using mediator models or some other variant of linear hierarchical regression procedures). We opted against this possibility for at least three reasons. First, it has been formally shown that mediator models do not provide a test of the mediation assumption itself but inform us how variable relations would look if that assumption were true. Specifically, it has been formally shown that the degree to which the mediator predicts age-related variance in the DV is a quadratic function of the age-orthogonal relation between the mediator and the DV (Lindenberger \& Pötter, 1998). Thus, the information obtained by mediator models is less conclusive than it may appear. Second, the results of mediational analyses are especially difficult to interpret if the construct occupying the position of the mediator is factorially complex, as is probably the case for standard measures of perceptual speed (Bashore, Ridderinkhof, \& van der Molen, 1998). Under such conditions, a certain portion of the variance in the mediator construct may function as a cause of age differences in the DV, but some other portion may not. Given that these different portions of variance are confounded within a single variable (or construct), the net outcome of the analysis may represent a mixture of divergent effects and would consequently be hard to interpret. Finally, the use of linear hierarchical regression procedures is known to be problematic if relations among variables differ as a function of the independent variable (i.e., when the homoscedasticity assumption is violated). As reported, the relations of perceptual speed to general and specific aspects of task switching were higher in young adults $(r=-.61$ and $r=-.60$ ) than in old adults $(r=-.21$ and $r=-.15$; for the difference: general switch costs, $t=2.62, p<.01$; specific switch costs, $t=2.86$, $p<.01$ ). Thus, the current data violates the homoscedasticity assumption and are not well suited for mediational analyses.

\section{Limitations of the Present Findings}

The present findings may be influenced by the specific version of the switching paradigm. The first issue concerns the measurement of specific switch costs with an AABB design. One of the reviewers argued that the smaller age effects in specific relative to general switch costs could be an artifact of using AABB runs, because old adults need more time to disengage (or show more proactive interference) from previous switch trials than young adults. Thus, for older adults, the latencies of nonswitch trials may be larger because of a greater proportion of what is still due to the switching process. As a result, differences in latencies between switch and nonswitch trials would be smaller for older adults. Of course, with the AABB design it is not possible to distinguish whether specific switch costs reflect proactive interference (Allport et al., 1994) that arises from involuntary positive and negative priming from preceding trials (see Allport \& Wylie, in press) or an active reconfiguration process to set up the cognitive system for the next task (Monsell, 1996). The dynamic mentioned above, which would result in an underestimation of age differences in specific switch costs, is comparable to the paradoxical findings of Allport and colleagues who reported that switching from easier to difficult task sets produced larger costs than vice versa (Allport et al., 1994).

In any case, the general assumption for the above argument is that old adults differ from young adults in the proactive interference component during task switching. Thus, one would expect that specific switch costs differ as a function of task characteristics such as response repetition. For example, Rogers and Monsell (1995) reported highly significant interaction effects between response repetition and specific task switching in their experiments, that is, a benefit (i.e., facilitation effect) of repeating the same response in nonswitch trials but a cost (i.e., inhibition effect) of repeating the same response in switch trials. Thus, if our findings of age differences in specific switch costs are confounded with characteristics from preceding trials, we should observe an interaction of response repetition and specific task switching with age. Although we found a highly reliable interaction between task switching and response repetition in all three task domains, no significant interactions of 
this effect with age were observed. ${ }^{9}$ Thus, the source of age differences in task switching seems not to arise from specific deficits of old adults in inhibiting irrelevant and activating relevant task information.

Although there is good evidence that age effects in specific task switching are not a result of proactive interference within taskheterogeneous blocks, we cannot rule out the possibility that the magnitude of age differences in general task switching is influenced by previously given task-homogeneous blocks because there is also evidence that older adults have specific difficulties in disengaging from previous task-set "lists" (Mayr \& Liebscher, 1998). A systematic comparison of age differences in specific and general costs when heterogeneous and homogeneous blocks vary either within or between subjects is needed to examine this possibility.

The second issue relates to the absence of external cues, standing in contrast to most of the literature, in which alternating between cognitive tasks was externally cued. The main reason for not providing cues in the present study was to maximize the need for "internal" cognitive control. Based on theoretical considerations, we expected age differences in cognitive control primarily in task situations in which the cognitive system has to be regulated by internal, rather than external, cues.

\section{Conclusion and Outlook}

The present study discerned two separable components of cognitive control that show differential relations to age: General switch costs show greater increments with increasing age than specific switch costs. The reasons for this discrepancy are not yet fully understood. One possible explanation is that control processes in multistep tasks are mainly responsible for selecting among operations (see Monsell, 1996) with respect to the organization of processing (sequencing) and the content of processing (configuring). The organization of processing seems to be required in general task-switching situations, such as in task-heterogeneous trials of the present experiment, in which participants had to keep track of the task sequence because no cue was given for the currently relevant task. The findings of greater age differences in general than in specific task-switching situations suggests that impairments of older adults are more strongly related to the organization of cognitive processing within working memory than to the specific dynamics of activating relevant and inhibiting irrelevant stimulus-response sets. This conclusion was further confirmed by additional analysis, that is, interaction of task switching and response repetition, indicating that old adults have no specific deficits to actively reconfigure the cognitive system from one moment to the next.

Future research is needed to clarify the observed age dissociation between general and specific task-switching performance. One major limitation of the present paradigm is that the measured control components, albeit empirically separable, are theoretically not independent of each other. This problem was already mentioned by Brinley (1965), who argued that the constructs of set shifting and memory are difficult to separate because in order to shift between two or more sets, it is also necessary to keep them in mind. The same problem also occurs in dual-task settings in which the ability to coordinate or manage two or more tasks also involves the ability to switch between them (Hawkins et al., 1992). A related problem is that the increase in task sets from one (homogeneous blocks) to two (heterogeneous blocks) also increases the complexity of the stimulus-response mappings because responses of both tasks were mapped onto the same response keys. Future attempts at theorizing and experimentation (e.g., Allport \& Wylie, in press) should try to overcome these difficulties in order to find out why differences in processing speed between task-set homogeneous and task-set heterogeneous situations increase with age.

\footnotetext{
${ }^{9}$ We computed an ANOVA with Age Group (3) as a between-subject factor, and Switch Type (Nonswitch-Switch), Response Type (SameDifferent) as within-subject factors separately for each task domain (numerical, figural, verbal). The interaction of task switching and response repetition was statistically reliable for all three task domains (for numerical tasks: Switch Type $\times$ Response Type: $F(1,115)=81.33, M S E=0.01$, $p<.01, \eta^{2}=.41$, for figural tasks: Switch Type $\times$ Response Type: $F(1$, $115)=124.07, M S E=0.02, p<.01, \eta^{2}=.52$, for verbal tasks: Switch Type $\times$ Response Type: $F(1,115)=101.54, M S E=0.01, p<.01, \eta^{2}=$ .47 ), indicating that in switch trials, repetitions of the same response produced longer latencies than nonrepetitions. In nonswitch trials, either the difference was in the opposite direction or the difference was absent. Interactions with the two contrasts of Age Group were not reliable, all $p \mathrm{~s}>$ .15 .
}

\section{References}

Allport, A., Styles, E. A., \& Hsieh, S. (1994). Shifting intentional set: Exploring the dynamic control of tasks. In C. Umiltà \& M. Moscovitch (Eds.), Attention and performance XV (pp. 421-452). Cambridge, MA: MIT Press.

Allport, A., \& Wylie, G. (in press). Task-switching: Positive and negative priming of task-set. In G. W. Humphreys, J. Duncan, \& A. M. Treisman (Eds.), Attention, space and action: Studies in cognitive neuroscience. Oxford, England: Oxford University Press.

Baddeley, A. (1986). Working memory. Oxford, England: Clarendon Press. Baddeley, A. (1996). Exploring the central executive. The Quarterly Journal of Experimental Psychology, 49, 5-28.

Baltes, P. B. (1993). The aging mind: Potential and limits. The Gerontologist, 33, 580-594.

Baltes, P. B., Cornelius, S. W., Spiro, A., Nesselroade, J. R., \& Willis, S. L. (1980). Integration versus differentiation of fluid/crystallized intelligence in old age. Developmental Psychology, 16, 625-635.

Baltes, P. B., \& Kliegl, R. (1992). Further testing of limits of cognitive plasticity: Negative age differences in a mnemonic skill are robust. Developmental Psychology, 28, 121-125.

Baltes, P. B., \& Lindenberger, U. (1997). Emergence of a powerful connection between sensory and cognitive functions across the adult life span: A new window to the study of cognitive aging? Psychology and Aging, 12, 12-21.

Baltes, P. B., Reese, H. W., \& Nesselroade, J. R. (1988). Life-span developmental psychology: Introduction to research methods (2nd ed.). Hillsdale, NJ: Erlbaum.

Baltes, P. B., Staudinger, U. M., \& Lindenberger, U. (1999). Lifespan psychology: Theory and application to intellectual functioning. Annual Review of Psychology, 50, 471-535.

Bashore, T. R., Ridderinkhof, K. R., \& van der Molen, M. W. (1998). The decline of cognitive processing speed in old age. Current Directions, 6 , 163-169.

Bentler, P. M. (1989). EQS Structural equations manual. Los Angeles, CA: BMDP Statistical Software.

Brinley, J. F. (1965). Cognitive sets, speed and accuracy of performance in 
the elderly. In A. T. Welford \& J. E. Birren (Eds.), Behavior, aging, and the nervous system (pp. 114-149). Springfield: Charles C Thomas.

Cerella, J., Poon, L. W., \& Williams, D. M: (1980). Aging and the complexity hypothesis. In L. W. Poon (Ed.), Aging in the 1980's: Psychological issues (pp. 332-340). Washington, DC: American Psychological Association.

Chapman, L. J., Chapman, J. P., Curran, T. E., \& Miller, M. B. (1994). Do children and the elderly show heightened semantic priming? How to answer the question. Developmental Review, 14, 159-185.

Chown, S. M. (1961). Age and the rigidities. Journal of Gerontology, 16, 353-362.

Cohen, J. (1977). Statistical power analysis for the behavioral sciences (rev. ed.). New York: Academic Press.

Craik, F. I. M. (1986). A functional account of age differences in memory. In F. Klix \& H. Hagendorf (Eds.), Human memory and cognitive capabilities, mechanisms, and performance. Amsterdam: North Holland.

Dempster, F. N. (1992). The rise and fall of the inhibitory mechanism: Toward a unified theory of cognitive development and aging. Developmental Review, 12, 45-75.

Duncan, J. (1995). Attention, intelligence, and the frontal lobes. In M. S. Gazzaniga (Ed.), The Cognitive Neuroscience (pp. 721-733). Cambridge, MA: MIT Press.

Ferraro, F. R., \& Moody, J. (1996). Consistent and inconsistent performance in young and elderly adults. Developmental Neuropsychology, 12, 429-441.

Fisk, J. E., \& Warr, P. (1996). Age and working memory: The role of perceptual speed, the central executive, and the phonological loop. Psychology and Aging, 11, 316-323.

Frensch, P. A., Lindenberger, U., \& Kray, J. (1999). Imposing structure on an unstructured environment: Ontogenetic changes in the ability to form rules of behavior under conditions of low environmental predictability. In A. Friederici \& R. Menzel (Eds.), Learning: Rule extraction and representation. Berlin, Germany: De Gruyter.

Geary, D. C., \& Wiley, J. G. (1991). Cognitive addition: Strategy choice and speed-of-processing differences in young and elderly adults. Psychology and Aging, 6, 474-483.

Hawkins, H. L., Kramer, A. F., \& Capaldi, D. (1992). Aging, exercise, and attention. Psychology and Aging, 7, 643-653.

Hertzog, C., Cooper, B. P., \& Fisk, A. D. (1996). Aging and individual differences in the development of skilled memory performance. Psychology and Aging, 11, 497-520.

Houx, P. J., Jolles, J., \& Vreeling, F. W. (1993). Stroop interference: Aging effects assessed with the Stroop color-word test. Experimental Aging Research, 19, 209-224.

Jensen, A. R. (1987). Process differences and individual differences in some cognitive tasks. Intelligence, 11, 107-136.

Jersild, A. T. (1927). Mental set and shift. Archives of Psychology (Whole No. 89).

Kliegl, R., \& Baltes, P. B. (1987). Theory-guided analysis of mechanisms of development and aging through testing-the-limits and research on expertise. In C. Schooler \& K. W. Schaie (Eds.), Cognitive functioning and social structure over the life course (pp. 95-119). Norwood, NJ: Ablex.

Kliegl, R., Mayr, U., \& Krampe, R. T. (1994). Time-accuracy functions for determining process and person differences: An application to cognitive aging. Cognitive Psychology, 26, 134-164.

Korteling, J. (1993). Effects of age and task similarity on dual-task perfornance. Human Factors, 35, 99-114.

Kramer, A. F., Hahn, S., \& Gopher, D. (1999). Task coordination and aging: Explorations of executive control processes in the task switching paradigm. Acta Psychologica, 101, 339-378.

Kramer, A. F., Larish, J. F., \& Strayer, D. L. (1995). Training for attentional control in dual task settings: A comparison of young and old adults. Journal of Experimental Psychology: Applied, 1, 50-76.
Lima, S. D., Hale, S., \& Myerson, J. (1991). How general is general slowing? Evidence from the lexical domain? Psychology and Aging, 6, 416-425.

Lindenberger, U., \& Baltes, P. B. (1995). Testing-the-limits and experimental simulation: Two methods to explicate the role of learning in development. Human Development, 38, 349-360.

Lindenberger, U., \& Baltes, P. B. (1997). Intellectual functioning in old and very old age: Cross-sectional results from the Berlin Aging Study. Psychology and Aging, 12, 410-432.

Lindenberger, U., Mayr, U., \& Kliegl, R. (1993). Speed and intelligence in old age. Psychology and Aging, 8, 207-220.

Lindenberger, U., \& Pötter, U. (1998). The complex nature of unique and shared effects in hierarchical linear regression: Implications for developmental psychology. Psychological Methods, 3, 218230.

Mayr, U., \& Kliegl, R. (1993). Sequential and coordinative complexity: Age-based processing limitations in figural transformations. Joumal of Experimental Psychology: Learning, Memory, and Cognition, 19, 12971320.

Mayr, U., Kliegl, R., \& Krampe, R. T. (1996). Sequential and coordinative processing dynamics in figural transformations across the life span. Cognition, 59, 61-90.

Mayr, U., \& Liebscher, T. (1998). Is task-set disengagement an active process? Evidence from cognitive aging. Manuscript submitted for publication.

Meiran, N. (1996). Reconfiguration of processing mode prior to task performance. Journal of Experimental Psychology: Learning, Memory, and Cognition, 22, 1423-1442.

Meiran, N., Gotler, A., \& Perlman, A. (1998). Old age is associated with a pattern of relatively intact and relatively impaired task set switching abilities. Manuscript submitted for publication.

Meng, X.-L., Rosenthal, R., \& Rubin, D. B. (1992). Comparing correlated correlation coefficients. Psychological Bulletin, 111, 172-175.

Meredith, W. (1993). Measurement invariance, factor analysis, and factorial invariance. Psychometrika, 58, 525-543.

Monsell, S. (1996). Control of mental processes. In V. Bruce (Ed.), Unsolved mysteries of the mind (pp. 93-148). Hove: Erlbaum.

Norman, D. A., \& Shallice, T. (1986). Attention in action: Willed and automatic control of behavior. In R. J. Davidson, G. E. Schwartz, \& D. Shapiro (Eds.), Consciousness and self-regulation (Vol. 4, pp. 1-18). New York: Plenum Press.

Park, D. C., Lautenschlager, G., Smith, A. D., \& Earles, J. L. (1996). Mediators of long-term memory performance across the life span. Psy. chology and Aging, 11, 621-637.

Prull, M. W., Gabrieli, J. D. E., \& Bunge, S. A. (in press). Age-related changes in memory: A cognitive neuroscience perspective. In F. I. M. Craik \& T. A. Salthouse (Eds.), The handbook of psychology and aging II. Mahwah, NJ: Erlbaum.

Ratcliff, R. (1993). Methods for dealing with reaction time outliers. Psychological Bulletin, 114, 510-532.

Raven, J. C., Court, J. H., \& Raven, J. (1987). A manual for Raven's Progressive Matrices and Vocabulary Tests. London: H. K. Lewis.

Reinert, G. (1970). Comparative factor analytic studies of intelligence throughout the life span. In L. R. Goulet \& P. B. Baltes (Eds.), Life-span developmental psychology: Research and theory (pp. 476-484). New York: Academic Press.

Reitan, R., \& Wolfson, D. (1994). A selective and critical review of neuropsychological deficits and the frontal lobes. Neuropsychology Review, 4, 161-197.

Rogers, R. D., \& Monsell, S. (1995). Costs of a predictable switch between simple cognitive tasks. Journal of Experimental Psychology: General, 124, 207-231.

Rushton, J. P., Brainerd, C. J., \& Pressley, M. (1983). Behavioral devel- 
opment and construct validity: The principle of aggregation. Psychological Bulletin, 94, 18-38.

Salthouse, T. A. (1988). The complexity of age by complexity functions: Comment on Charness and Campbell (1988). Joumal of Experimental Psychology: General, 117, 425-428.

Salthouse, T. A. (1991). Theoretical perspectives on cognitive aging. Hillsdale, NJ: Erlbaum.

Salthouse, T. A. (1996). Constraints on theories of cognitive aging. Psychonomic Bulletin and Review, 3, 287-299.

Salthouse, T. A., Fristoe, N. M., McGuthry, K. E., \& Hambrick, D. Z. (1998). Relation of task switching to speed, age, and fluid intelligence. Psychology and Aging, 13, 445-461.

Salthouse, T. A., Hambrick, D. Z., Lukas, K. E., \& Dell, T. C. (1996). Determinants of adult age differences on synthetic work performance. Journal of Experimental Psychology: Applied, 2, 1-25.

Salthouse, T. A., \& Meinz, E. J. (1995). Aging, inhibition, working memory, and speed. Journal of Gerontology: Psychological Sciences, 50, 297-306.

Schaie, K. W. (1996). Intellectual development in adulthood: The Seattle Longitudinal Study. New York: Cambridge University Press.

Schaie, K. W., Dutta, R., \& Willis, S. L. (1991). Relationship between rigidity-flexibility and cognitive abilities in adulthood. Psychology and Aging, 6, 371-383.

Schaie, K. W., Maitland, S. B., Willis, S. L., \& Intieri, R. C. (1998). Longitudinal invariance of adult psychometric ability factor scores across 7 years. Psychology and Aging, 13, 8-20.

Shallice, T., \& Burgess, P. (1993). Supervisory control of action and thought selection. In A. Baddeley \& L. Weiskrantz (Eds.), Attention: Selection, awareness, and control (pp. 171-187). Oxford, England: Clarendon Press.
Sliwinski, M., Buschke, H., Kuslansky, G., Senior, G., \& Scarisbrick, D. (1994). Proportional slowing and addition speed in old and young adults. Psychology and Aging, 9, 72-80.

Spearman, C. E. (1927). The abilities of man. New York: MacMillan. Spieler, D. H., Balota, D. A., \& Faust, M. E. (1996). Stroop performance in healthy younger and older adults and individuals with dementia of the Alzheimer's type. Joumal of Experimental Psychology: Human Perception and Performance, 22, 461-479.

Stroop, J. R. (1935). Studies of interference in serial verbal reactions. Journal of Experimental Psychology, 18, 643-662.

Stuss, D. T., Eskes, G. A., \& Foster, J. K. (1994). Experimental neuropsychological studies of frontal lobe functions. In F. Boller, $\mathrm{H}$. Spinnler, \& J. A. Hendler (Eds.), Handbook of Neuropsychology (pp. 149-185). Amsterdam: Elsevier.

Tranel, D., Anderson, S. W., \& Benton, A. (1994). Development of the concept of "executive function" and its relationship to the frontal lobes. In F. Boller, H. Spinnler, \& J. A. Hendler (Eds.), Handbook of neuropsychology (pp. 125-148). Amsterdam: Elsevier.

Van der Linden, M., Brédart, S., \& Beerten, A. (1994). Age-related differences in updating working memory. British Journal of Psychology, $85,145-152$.

Verhaeghen, P., Kliegl, R., \& Mayr, U. (1997). Sequential and coordinative complexity in time-accuracy functions for mental arithmetic. Psychology and Aging, 12, 555-564.

Verhaeghen, P., \& Salthouse, T. A. (1997). Meta-analyses of agecognition relations in adulthood: Estimates of linear and nonlinear age effects and structural models. Psychological Bulletin, 122, 231-249.

Wechsler, D. (1982). Handanweisung zum Hamburg-Wechsler Intelligenztest für Erwachsene (HAWIE) [Manual for the Hamburg-Wechsler Intelligence Test for Adults]. Bern, Switzerland: Huber. 
Appendix

Raw Latencies and Standard Errors
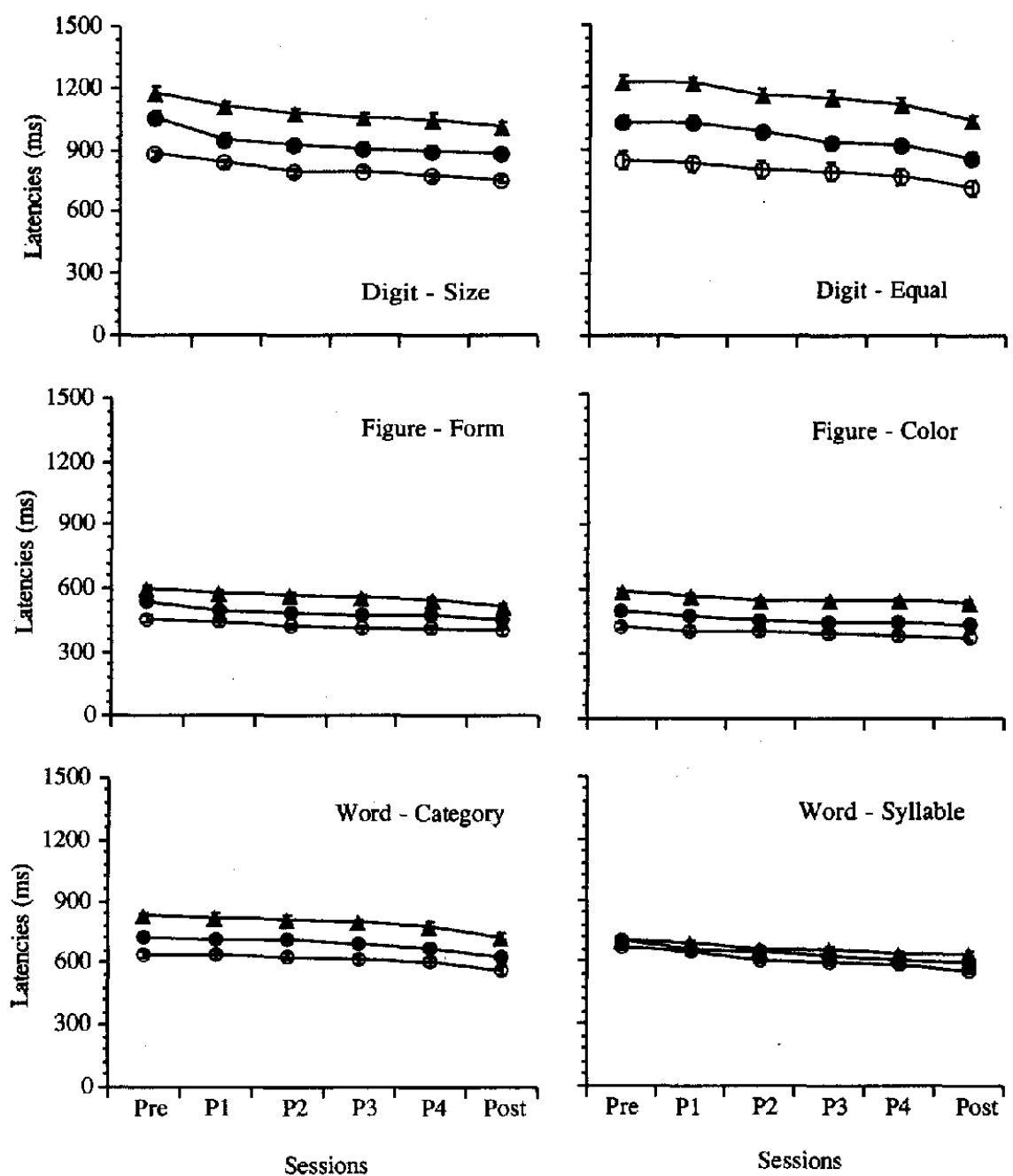

Figure A1. Raw latencies and standard errors of homogeneous tasks as a function of task, response stimulus interval, session, and age group (young, middle-aged, old). Open circles = young age group; solid circles = middle-aged group; solid triangles $=$ old age group. 

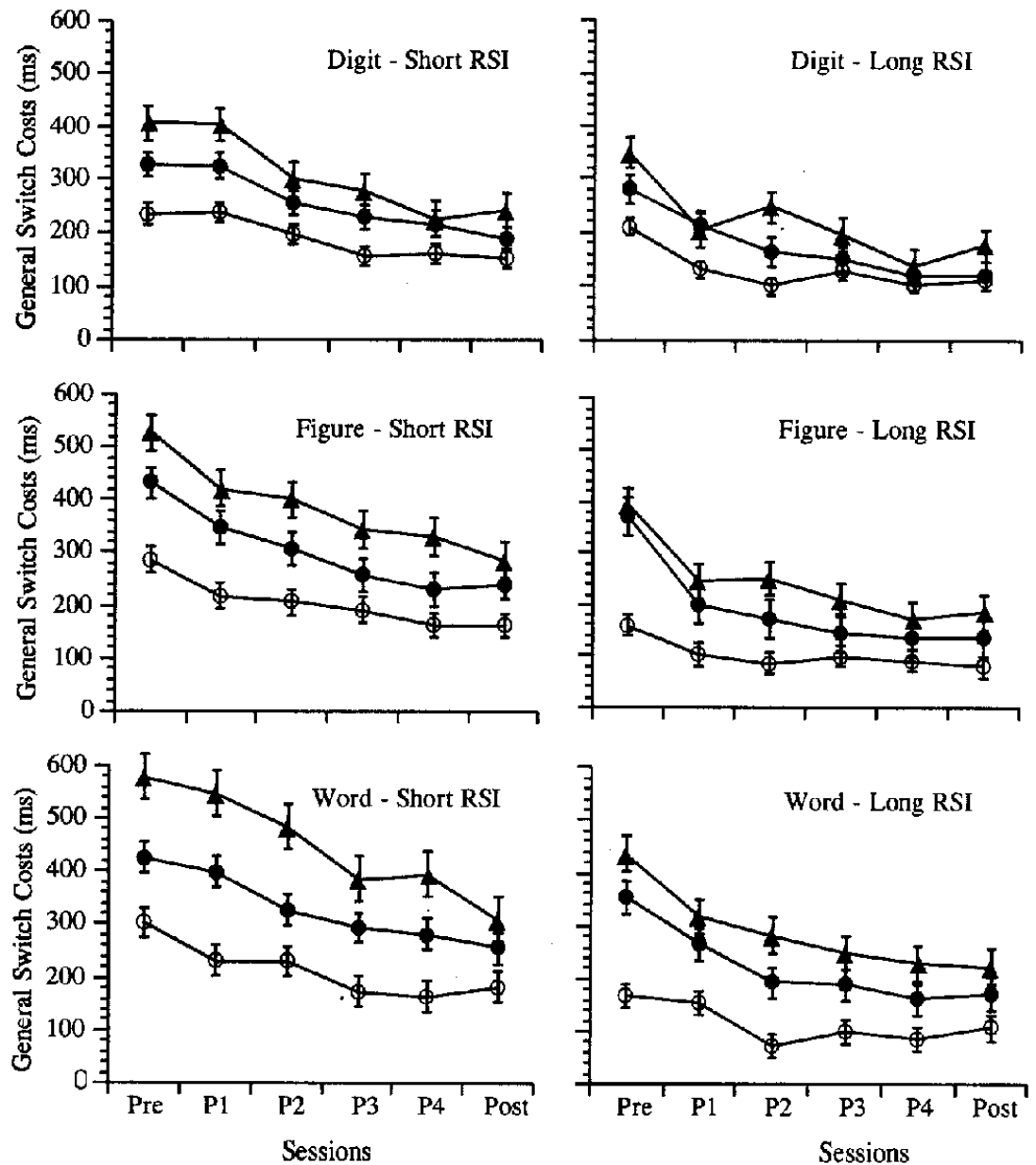

Figure A2. Raw latencies and standard errors of general switch costs as a function of task, response stimulus interval, session, and age group (young, middle-aged, old). Open circles = young age group; solid circles = middle-aged group; solid triangles = old age group. 

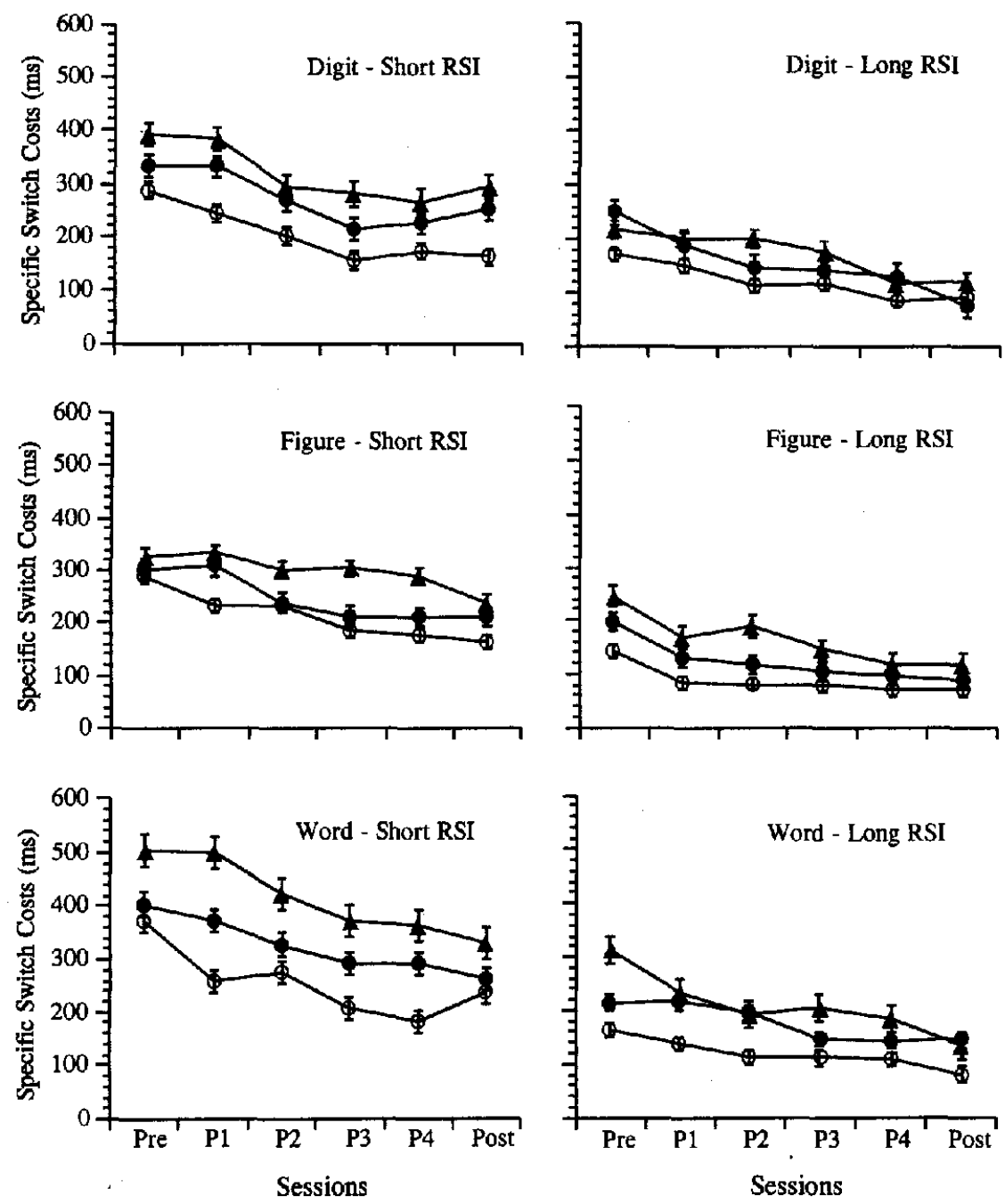

Figure A3. Raw latencies and standard errors of specific switch costs as a function of task, response stimulus interval, session, and age group (young, middle-aged, old). Open circles = young age group; solid circles = middle-aged group; solid triangles $=$ old age group.

Received September 16, 1998 Revision received June 25, 1999 